NASA Contractor Report 3196

\title{
Evaluation of a New Concept for Reducing Free-Stream Turbulence in Wind Tunnels
}

Roald A. Wigeland, Jimmy'Tan-atichat, and Hassan M. Nagib 
NASA Contractor Report 3196

\section{Evaluation of a New Concept for Reducing Free-Stream Turbulence in Wind Tunnels}

Roald A. Wigeland, Jimmy Tan-atichat, and Hassan M. Nagib

Illinois Institute of Technology

Cbicago, Illinois

Prepared for

Langley Research Center

under Grant NSG-1451

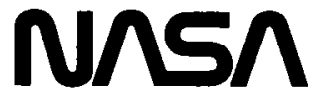

National Aeronautics

and Space Administration

Scientific and Technical

Information Branch 
-" 


\section{FOREWORD}

This work is just one of many performed over the last ten years at IIT on the management and control of free-stream turbulence, as well as other flow characteristics. During some of these studies we have especially concentrated on those which are typically found in wind tunnels. This work was particularly aimed at the development of techniques for improving the flow in many existing wind tunnels, as most of them have very short or no settling chamber ahead of the contraction. 


\section{TABLE OF CONTENTS}

Page

Foreword . . . . . . . . . . . . . . . . . . . . . . . . iii

List of Figures . . . . . . . . . . . . . . . . . . . . . . vi

Introduction . . . . . . . . . . . . . . . . . . . . . . I

Test Facilities and Instrumentation . . . . . . . . . . . . 4

Wind Tunnel Characteristics . . . . . . . . . . . . 4

Instrumentation . . . . . . . . . . . . . . . . . . 4

Scaling of $5 \mathrm{~m}$ TDT Turning Vanes . . . . . . . . . . . 5

Construction of $90^{\circ}$ Corner Scale Model . . . . . . . . 6

Test Flow Conditions . . . . . . . . . . . . . . 6

Manipulator Selection and Construction . . . . . . . . 7

Experimental Results . . . . . . . . . . . . . . . . . 9

Flow Downstream of the Turning Vanes . . . . . . . . . 9

Effect of a $45^{\circ}$ Screen . . . . . . . . . . . . . . . . 12

$45^{\circ}$ Honeycomb and $45^{\circ}$ Screen . . . . . . . . . . . . . 13

Effect of Separation Between Turning Vanes and

$45^{\circ}$ Honeycomb. . . . . . . . . . . . . . . . . . . 15

Effect of $45^{\circ}$ Honeycomb Mesh Size . . . . . . . . . . 16

Effect of Free-Stream Velocity on $45^{\circ}$ Honeycomb

Performance . . . . . . . . . . . . . . . . . 18

Relative Effectiveness of Different Types of

Turbulence Manipulators . . . . . . . . . . . . . . 18

Summary . . . . . . . . . . . . . . . . . . 20

Conclusion . . . . . . . . . . . . . . . . . . . . . . 23

References . . . . . . . . . . . . . . . . . . . 26

Figures . . . . . . . . . . . . . . . . . . . . 27 


\section{LIST OF FIGURES}

Figure 1. Schematic of proposed "new-concept" $45^{\circ}$ honeycomb and comparison with a conventional honeycomb . . . . . . . . . . . . . . . . . . . . 27

Figure 2. Photograph of scale-model turning vanes mounted in a $90^{\circ}$ corner . . . . . . . . . . . . . . . . .

Figure 3. Lateral profiles of mean velocity and turbulence intensity at several distances downstream of turning vanes with low upstream turbudence . . . . . .

Figure 4. Lateral profiles of mean velocity with either a conventional honeycomb or no flow manipulator downstream of turning vanes in several flow conditions . . . . . .

Figure 5. Lateral profiles of turbulence intensity with either a conventional honeycomb or no flow manipulator downstream of turning vanes in several flow conditions. .

Figure 6. Lateral profiles of mean velocity and turbulence intensity at several distances downstream of turning vanes with a $0.91 \mathrm{~mm}$ mesh $45^{\circ}$-screen positioned at trailing edges of turning vanes in low turbulence flow condition.

Figure 7. Lateral profiles of mean velocity and turbulence intensity with a $3.13 \mathrm{~mm}$ mesh $45^{\circ}$-honeycomb positioned at trailing edges of turning vanes with and without a $0.91 \mathrm{~mm}$ mesh $45^{\circ}$-screen at downstream end of honeycomb in low turbulence flow condition . . . . . . . . . . .

Figure 8. Lateral profiles of mean velocity and turbulence intensity for two distances downstream of turning vanes with a $45^{\circ}$ honeycomb-450-screen positioned at trailing edges of turning vanes in low turbulence flow condition

Figure 9. Effect of separation between $45^{\circ}$ honeycomb-45 screen combination and trailing edges of turning vanes on lateral profiles of mean velocity and turbulence intensity in high turbulence flow condition . . . . . . .

Figure 10. Effect of $45^{\circ}$-honeycomb mesh on lateral profiles of mean velocity for a $45^{\circ}$ honeycomb $-45^{\circ}$ screen combination with no separation from turning vanes, $\Delta x=0$, and $\Delta x=5.0 \mathrm{~cm}$ in high turbulence flow condition . . . . . .

Figure 11. Effect of $45^{\circ}$-honeycomb mesh on lateral profiles of turbulence intensity for a $45^{\circ}$ honeycomb-45 screen combination with no separation from turning vanes, $\Delta x=0$, and $\Delta x=5.0 \mathrm{~cm}$ in high turbulence test flow condition . . 
Figure 12. Lateral profiles of mean velocity and turbulence intensity for three free-stream velocities with a $45^{\circ}$ honeycomb-45 $5^{\circ}$ screen combination downstream of turning vanes and separation $\Delta x=5.0 \mathrm{~cm}$. . . . . . . 38

Figure 13. Effect of using no manipulator, a $45^{\circ}$-screen, a conventional honeycomb-screen combination, and a $45^{\circ}$ honeycomb-45 screen combination downstream of turning vanes on lateral profile of mean velocity in low turbulence flow condition . . . . . . . . . . . . . . .

Figure 14. Effect of using no manipulator, a $45^{\circ}$-screen, a conventional honeycomb-screen combination, and a $45^{\circ}$ honeycomb $-45^{\circ}$ screen combination downstream of turning vanes on lateral profile of turbulence intensity in low turbulence flow condition . . . . . . . . . . . . . . . .

Figure 15. Effect of using no manipulator, a $45^{\circ}$-screen, a conventional honeycomb-screen combination, and a $45^{\circ}$ honeycomb $-45^{\circ}$ screen combination downstream of turning vanes on lateral profile of mean velocity in high turbulence flow condition . . . . . . . . . . . . . . .

Figure 16. Effect of using no manipulator, a $45^{\circ}$-screen, a conventional honeycomb-screen combination, and a 45 honeycomb-45 screen combination downstream of turning vanes on lateral profile of turbulence intensity in high turbulence flow condition 


\section{INTRODUCTION}

Most experiments conducted in wind tunnels require a low turbulence intensity in the test section, with good spatial uniformity of both the mean velocity and the turbulence intensity. Recent proposed experiments, such as laminar flow control (LFC), Impose a severe restriction on the maximum allowable turbulence level in the test section. According to $\mathrm{Dr}$. W. Pfenninger, of NASA LaRC, turbulence intensities of less than $0.1 \%$ will be required.

Due to recent work in the area of turbulence control and management, $1,2,3$ as well as on control of secondary flows in ducts $4,5,6$ this level is not unattainable under certain conditions. Specifically, efficient compact combinations of honeycombs, grids, screens and other flow manipulators have been developed which lead to substantial reductions in the free-stream turbulence levels with a minimum of power loss due to manipulator pressure drop. The optimum arrangements depend on maximization of the manipulator turbulence suppression functions and minimization of their generation functions. $1,2,3$ In particular, the important role of the shear layer instabilities and the proper balance between the different scales of the manipulator and the turbulence are considered in the design of efficient manipulator combinations. 2,3 In most cases, available power limitations of the facility make the use of these combinations desirable, if not mandatory, to achieve the required turbulence level.

However, another extremely important feature of using these flow manipulator combinations is the provision for adequate decay distance between manipulators as well as downstream of the final manipulator ahead of the contraction. Unfortunately, most wind tunnels have little, if any, settling chamber between the turning vanes and the start of the contraction. This lack of any appreciable settling chamber has a severe restrictive effect on the type and number of manipulators that can be used for improving the turbulence level, with subsequent limits on the amount of turbulence reduction that can be accomplished. While 
new wind tunnel facilities are, or should be, designed with a settling chamber long enough for proper turbulence management, and some older facilities can be modified to provide an adequate settling chamber for maximum reduction in the test section turbulence intensity, there are many wind-tunnels, especially those of large cross-sectional area, that cannot be modified. The LaRC/5m TDT is one of these tunnels.

Since new large facilities are extremely expensive, efforts are underway in several facilities to improve performance of these short settling chamber wind tunnels for present-day experiments, such as LFC. In particular, the LaRC/5m TDT was being considered as a possible facility for conducting LFC experiments. While no reliable measurements of turbulence intensity are available for the test section, realistic estimates indicate a level much higher than the $0.1 \%$ required for LFC experiments, probably $0.3-0.5 \%$. These estimates are based on the turbulence decay downstream of the last set of turning vanes ahead of the contraction. This indicates the necessity of a substantial turbulence reduction in the test section with essentially no appreciable settling chamber length to allow for the flow manipulators and the turbulence decay. As one method of possibly overcoming this situation, a "new concept" honeycomb was proposed.

In the conventional method of installing honeycombs, screens and grids in the wind tunnel, the plane of the manipulator is normal to the mean flow. This results in the manipulator being closer to the turning vanes at the inside of the corner and further away at the outside of the corner. This situation is depicted in Figure 1. There is a much larger distance at the outside of the corner over which the turbulence and wakes from the turning vanes decays. From the point of view of turbulence control, this additional distance is wasted, especially in wind tunnels with little settling chamber distance. Instead of using this distance for the decay of the "uncontrolled" flow characteristics due to the turning vanes, the "new concept" honeycomb uses it for additional decay of the modified, and usually improved (i.e., 
faster decaying and of more appropriate scales), turbulence downstream of the manipulator. This arrangement is also depicted in Figure 1. Note that the cells of the honeycomb are still aligned with the mean flow direction, although the plane of the honeycomb is now parallel to the plane of the turning vanes at 45 degrees to the mean flow direction. For this reason the "new concept" honeycomb will also be referred to as the $45^{\circ}$ honeycomb. Although this type of honeycomb is more expensive, there is an additional advantage in that the $45^{\circ}$ honeycomb can be supported by the turning vanes and thus eliminates the need for a separate support structure.

In light of the totally new nature of this manipulator, several experiments were performed to evaluate the overall performance characteristics and optimize the parameters involved. Of particular interest is the relative effectiveness of the $45^{\circ}$ honeycomb (and $45^{\circ}$ screen combination) in comparison with the conventional honeycomb (and screen combination). The majority of the experiments were conducted to reveal the turbulence reduction mechanisms, document the effectiveness of the "new concept" honeycomb and to provide information as to whether or not the $45^{\circ}$ honeycomb (and $45^{\circ}$ screen combination) is a viable alternative to the conventional honeycomb (and screen).

The authors wish to express their gratitude to several people involved with this project. In particular, W. Don Harvey as the technical monitor was very helpful to us in establishing the project and through discussions as the project was being carried out. We would like to thank Dennis Bushnell who was partly responsible for the project being initiated. We are also very grateful to Valerie Mattioli for her expert typing of the manuscript and to $A$. Curtis Crawford for the excellent work in constructing the test facilities. 


\section{TEST FACILITIES AND INSTRUMENTATION}

In order to evaluate the proposed "new concept" $45^{\circ}$ honeycomb$45^{\circ}$ screen combination, a scale model of the $90^{\circ}$ corner and turning vanes of the NASA LaRC/5m TDT was used. Based on the results of the scaling process, which will be discussed further in this section, a small open circuit wind tunnel was selected for the experiments.

\section{Wind Tunnel Characteristics}

The wind tunnel was powered by a blower which exhausted into the upstream end of its settling chamber. Velocities in excess of $75 \mathrm{~m} / \mathrm{sec}$ are possible in the test section, with the lower speeds being attained by throttling the blower output. Several flow manipulators are located in the settling chamber in order to spatially uniformize the flow velocities and for turbulence control. The test section is located downstream of a 25 to 1 contraction and is assembled using various lengths of plexiglas tube of circular cross-section, $15 \mathrm{~cm}$ in diameter. Every section has a flange on each end, so that as many sections as desired can be bolted together to form the test section. The flow characteristics in the test section are readily modified due to this modular construction by insertion of flow manipulators either inside the duct or between two sections. This design also makes it extremely easy to modify the wind tunnel test section for investigation of any type of ducted flow, such as that through a $90^{\circ}$ corner. The open circuit design also facilitates complete probing of the flow from the downstream end, with probe positioning being accomplished using the motorized 3-dimensional traversing mechanism available with this tunnel.

\section{Instrumentation}

Standard hot-wire instrumentation was used for all of the detailed velocity measurements. Single wire probes were operated in the constant temperature mode, along with linearizers to provide output directly proportional to the velocity in the test section. When the situation required, $x-$ wire probes and analog processing 4. 
circuits were used to resolve the three velocity components. The data in this report are presented in the form of traverses across the test section, which are extremely important for evaluating the flow characteristics in the full scale settling chamber and test section. The traverses were obtained using an $x-y$ plotter, with one axis related to the probe position and the other related to the quantity being measured, either mean velocity or turbulence intensity.

Scaling of $5 \mathrm{~m}$ TDT Turning Vanes

To adequately represent the flow through the $90^{\circ}$ corner including the turning vanes, a sufficient number of turning vanes, preferably greater than 6, were to be installed. Given the $15 \mathrm{~cm}$ diameter of the test section, there was approximately $21.6 \mathrm{~cm}$ available along the $45^{\circ}$ joint in the $90^{\circ}$ corner. The largest vane spacing was determined as $3.5 \mathrm{~cm}$ for 6 turning vanes, giving a geometric scale of approximately 8 to 1 between the full-scale and model facility.

To determine the upper limit of the scale ratio, the fullscale Reynolds numbers were taken into account. With full-scale Reynolds numbers in the range from $1 \times 10^{6}$ to $1.9 \times 10^{6}$, based on the chord of the turning vanes, it was obvious that this could not be approached in our modeling. However, the main influence of the chord Reynolds number is to make the boundary layers sufficiently turbulent. In a scale model of the turning vanes, a Reynolds number of $1 \times 10^{5}$ was thought to be sufficient to provide adequate turbulence in the boundary layers. Even if the initial experiments indicated that this was not the case, the turning vane boundary layers could be tripped. These Reynolds numbers resulted in a maximum scale of approximately 12 to 1 .

Another important restriction existed for the mesh Reynolds number of the honeycombs and other turbulence manipulators. Based on $6.25 \mathrm{~mm}$ and $12.5 \mathrm{~mm}$ mesh honeycombs for the full-scale tunnel, the mesh Reynolds number varied from $1 \times 10^{4}$ to $4 \times 10^{4}$. For the model, a minimum mesh Reynolds number of $4 \times 10^{3}$ was required to ensure turbulent flow in each cell of the honeycomb, as it certainly 
would be for the full-scale tunnel. In order to satisfy this requirement, the honeycomb meshes for the model facility were selected as $6.25 \mathrm{~mm}$ and $3.13 \mathrm{~mm}$, with $1.56 \mathrm{~mm}$ mesh being acceptable, but its Reynolds number was as low as 2500 at the lower speeds.

As a result of these scaling considerations, a prototype to model ratio in the range from $8: 1$ to $12: 1$ was required. To make the final decision on the scale, an estimate of the mesh range of possible full-scale tunnel honeycombs was made. Honeycombs in the range from $6.25 \mathrm{~mm}$ to $62.5 \mathrm{~mm}$ would certainly be considered for modifying the full-scale wind tunnel, with the larger meshes being positioned closer to the turning vanes. Using the $1.56,3.13$ and $6.25 \mathrm{~mm}$ mesh honeycombs in the model facility, it was decided to use a 12:1 ratio for the prototype to model ratio; i.e., $1.0 \mathrm{~m}$ in the full-scale wind tunnel corresponding to $8.33 \mathrm{~cm}$ in the model facility.

Construction of $90^{\circ}$ Corner Scale Model

Using a $12: 1$ scale ratio, it was possible to place 8 turning vanes in the $90^{\circ}$ corner, given the $30 \mathrm{~cm}$ spacing of the turning vanes in the full-scale wind tunnel. The $90^{\circ}$ corner was constructed from the same plexiglas tube used for the test section. The turning vanes are $1 / 12$ scale models of the prototype full-scale turning vanes, based on the original engineering drawings. The turning vanes are made of mahogany and conform quite well to the prototype. These turning vanes mounted in the $90^{\circ}$ corner are shown in Figure 2. This section is assembled into the wind tunnel test section for the purpose of performing the experiments. To make the experiments sufficiently general, several flow conditions upstream of the turning vanes were used.

\section{Test Flow Conditions}

The flow through the test section in its usual configuration has a turbulence intensity less than $0.5 \%$, especially at higher speeds due to the more efficient blower operation. It was realized that the conditions in the prototype wind tunnel would most likely 
not be as good as this, being of somewhat higher turbulence and possibly contaminated by upstream swirl. To simulate these conditions, a coarse grid upstream of the turning vanes was used to generate turbulence of about $3-4 \%$ intensity at the turning vanes. This flow condition is referred to as the "high upstream turbulence" flow condition in the rest of the report. The upstream swirl was generated using the airfoil swirl generator. This generator utilizes two adjacent airfoils, each spanning half of the test section, and set at adjustable equal but opposite angles of attack. A grid was also used in this flow condition to provide additional background turbulence. This flow condition is referred to as the "upstream swirl" flow condition. The third flow condition is the "low upstream turbulence" flow condition utilizing the flow as it usually exists in the test section without modification by flow manipulators.

Manipulator Selection and Construction

As mentioned above, honeycomb meshes of $6.25,3.13$ and 1.56 $\mathrm{mm}$ mesh were planned for the experiments. Generally, the length to diameter ratio of the honeycomb is about 10 for efficient operation, resulting in lengths of $62.5 \mathrm{~mm}$ and $31.3 \mathrm{~mm}$ for the 6.25 and $3.13 \mathrm{~mm}$ mesh honeycombs, respectively. To provide adequate strength for the $1.56 \mathrm{~mm}$ mesh honeycomb, a length of $25.4 \mathrm{~mm}$ was used. All of these mesh sizes were examined in the "new concept" $45^{\circ}$ configuration, but only the $3.13 \mathrm{~mm}$ mesh was incorporated in the conventional manner.

As discussed in much of the earlier work ${ }^{2,3}$, a screen in combination with the honeycomb can lead to much improved turbulence reduction. For this purpose, a $0.91 \mathrm{~mm}$ mesh screen was positioned downstream of the honeycomb in the conventional honeycomb case, as well as in the "new concept" $45^{\circ}$ honeycomb cases. For this purpose, a fixture was constructed which fits inside the plexiglas test section duct and holds a screen at $45^{\circ}$ to the mean flow downstream of the honeycomb and turning vanes. This is in contrast to the usual method of mounting such flow manipulators between sections of the test section in this tunnel. 
However, there still remained the problem of constructing the special "new concept" $45^{\circ}$ honeycomb. After much discussion, two methods were eventually used. The first involved having the manufacturer cut a $45^{\circ}$ angle on the honeycomb before it is expanded to its final form. There is enough rigidity in the compressed honeycomb for this to be done cleanly. However after the honeycomb is expanded, the edges of the honeycomb are not straight, but are somewhat of a saw-tooth shape. While this is not that objectionable, the process is expensive.

The other alternative is to take a straight honeycomb and to saw it at $45^{\circ}$ to the cell axes. There are several disadvantages to this method. First, there is a great deal of waste in the sections of the honeycomb not used, especially if any appreciable spanwise distance is to be covered. It also requires a honeycomb of fairly large length/cell diameter ratio. Another disadvantage is that the cell walls are not very rigid, and that the sawing operation leaves a rough edge (even folded over in some cases). No satisfactory method was established to saw the honeycomb cleanly in its expanded state. Careful hand sanding of the rough edges did provide a clean finish, but the process was very time consuming. 
EXPERIMENTAL RESULTS

The experiments were conducted according to the schematic shown in Figure 1. The open circuit design of the wind tunnel allowed easy access to the flow downstream of the turning vanes or any flow manipulators inserted in the duct. The three different upstream flow conditions (low turbulence, high turbulence and swirl) were generated as described in the previous section on the test facility and instrumentation. With the $90^{\circ}$ corner and the turning vanes mounted as part of the test section of the wind tunnel, the first step was to document the flow downstream of the turning vanes. For almost all of the experimental data, velocity profiles downstream of the turning vanes were taken along lines perpendicular to the mean flow, i.e., the ' $y$ ' direction as shown in Figure 1 . For wind tunnel applications, this direction is most appropriate, since the spatial uniformity in this direction of important flow characteristics, such as the turbulence intensity, will help assure a similar uniformity in the test section. A few profiles were also taken in the ' $z$ ' direction, perpendicular to the ' $x$ ' and ' $y$ ' directions, and the flow characteristics were quite uniform, as expected.

Flow Downstream of the Turning Vanes

The $90^{\circ}$ corner and turning vanes were mounted in the wind tunnel as shown in Figures 1 and 2 , with a low turbulence flow entering the turning vanes. Traverses in the ' $y$ ' direction were taken at several downstream positions, and the results are plotted in Figure 3 , where the downstream distance ' $x$ ' is defined with the origin at the inside corner of the $90^{\circ}$ turn which contains the turning vanes, as indicated on Figure 1. Please note the greatly expanded scale for the velocity axis of the profiles, which will be used in every case to accentuate whatever nonuniformities that may exist. The reader should also be cautioned about the behavior outside the central region of the duct, i.e., between dashed lines on figures. These regions are only useful for predicting the conditions near the walls of the full-scale settling chamber. From the profiles of the mean velocity $\bar{U}$, the wake of each turning 
vane is clearly evident, especially for the traverse taken at $x=3.13 \mathrm{~cm}$. The wakes become stronger as the value of $y$ decreases since the vanes are closer to the probe at the inside corner. This is a result of the turning vanes being at $45^{\circ}$ to the axis of the downstream duct, i.e., the ' $x$ ' direction, while the ' $y$ ' direction is at $90^{\circ}$ to this axis, as shown in Figure 1 . As one would expect, the wake defects become less noticeable as they merge, eventually resulting in a flow which is reasonably uniform at $x=21.6 \mathrm{~cm}$. The turbulence intensity $u^{\prime} / U_{\infty}$ also decreases and becomes more uniform as the distance from the turning vanes increases and the turbulence decays. For the definition of turbulence intensity, $u^{\prime} / U_{\infty}, u^{\prime}$ is the rms of the $U$ component velocity fluctuations, while $U_{\infty}$ is the spatial average of the mean velocity $\bar{U}$. The turbulence intensity is higher for negative values of $y$, again since there is less distance from the turning vanes to the probe location. These results indicate that the turning vanes operate as intended and that the flow characteristics downstream of these model turning vanes represent the expeoted full-scale situation. The accuracy of this representation depends on a comparison with fullscale data, which unfortunately were not available. The rate at which the wakes merge and the mechanism behind the process is extremely important for optimum placement of any flow manipulators and will be discussed later in this section.

To further document the flow conditions which were used for the experiments, the transverse distributions of mean velocity $\bar{U}$ and turbulence intensity $u^{\prime} / U_{\infty}$ are plotted in Figures 4 and 5 , respectively, for conditions of low upstream turbulence, high upstream turbulence, and upstream swirl. All of the results are for data taken at a probe location of $x=21.6 \mathrm{~cm}$, as this position approximates the average location of the start of the contraction for many wind tunnels (although many have shorter settling chambers and some are longer). Knowledge of the turbulence intensities at this location also approximates what would be entering the contraction after a rather short but not unreasonable decay distance from the last flow manipulator. Upon examining the data presented in Figures 4 and 5 , it 10. 
became apparent that the higher upstream turbulence results in spatially more uniform mean velocity and turbulence intensity distributions; with essentially no change in the turbulence level from the low upstream turbulence case. The presence of upstream swirl does not affect the mean velocity profile very much, (i.e., the downstream flow is quite similar to the low turbulence case) although the turbulence intensity is less uniform. Detailed measurements of the three velocity components proved that there was essentially no swirl emerging from the turning vanes, even though it was quite strong upstream of them. Based on these results, only the high and low upstream turbulence conditions were used for further experiments. These results also indicate that the turbulence in the settling chamber is dominated by that generated by the turning vanes. However, the role of upstream turbulence is important in the initial decay of the wakes from these vanes.

As the $45^{\circ}$ honeycomb concept is quite new, a means of evaluating its effect on the turbulence as compared with more conventional methods was desired. For this reason, a standard "conventional" honeycomb and low-solidity screen combination was used for both low and high upstream turbulence to develop the typical expected turbulence level. These results are also shown on Figures 4 and 5 for the mean velocity and turbulence intensity, respectively. It is apparent that the spatial uniformity of both the mean velocity and turbulence intensity is slightly improved for higher upstream turbulence. Approximately the same overall turbulence level is achieved by this manipulator for both high and low upstream turbulence conditions. Obviously, the results in both cases are improved over having the turning vanes alone. While this honeycombscreen combination is an efficient turbulence management solution, the actual solutions are usually more complicated, involving several flow manipulators. Even so, the data show that conditions in the test section are quite good, both in magnitude and uniformity, as well as being reasonably independent of upstream turbulence conditions, which is always desirable. Again, the important comparisons between figures are made here in the central part of the 
duct inside the two dashed lines.*

This completes the description of the basic flow conditions and the standard (or typical) turbulence improvement which is used as the basis for comparison with the results of the "new concept" honeycomb and screen combination, as well as other flow manipulators. The flow characteristics downstream of each flow manipulator (and combinations) are discussed in detail in the following for the two test flow conditions.

Effect of a $45^{\circ}$ Screen

It has been previously documented ${ }^{2,3}$ that the addition of a screen at the downstream end of a honeycomb substantially improves the effectiveness of the honeycomb in reducing the turbulence. Anticipating that a similar effect is present using a $45^{\circ}$ screen in combination with the $45^{\circ}$ honeycomb, a $45^{\circ}$ screen was made to be used either by itself or in a combination at the downstream end of the $45^{\circ}$ honeycomb, as discussed in the chapter on test facilities and instrumentation.

The use of a screen positioned along the downstream edges of the turning vanes has also been proposed as one means of modifying the turbulence as soon as it enters the settling chamber. It is also advantageous from an installation viewpoint, in that it would be much simpler to mount the screen along the downstream edges of the turning vanes than to stretch the screen across the entire settling chamber, especially in large wind tunnels. Both of these concepts were examined in this investigation. Using a section of the screen material selected for this experiment (an $0.91 \mathrm{~mm}$ mesh screen with a solidity of 0.35 ), measurements were taken downstream of the screen when it was positioned at the downstream edge of the turning vanes. The profiles of mean velocity and turbulence intensity at several downstream positions are plotted in Figure 6 . Examining the mean velocity profiles, the wake defect from some of the turning vanes

*The dashed lines on each figure correspond to those shown on Figure 1 , indicating the region of the duct which is influenced by the sidewall boundary layers. Between the dashed lines, the flow represents conditions that exist in the full-scale wind tunnel. 12 . 
is visible close to the turning vanes, but the wakes merge quickly with increasing downstream distance. At every downstream location, the wake defects are much less evident than they are with the turning vanes alone. However, there is another characteristic of these profiles which is very detrimental. Note that, at every downstream location, there is a persistent gradient in the mean velocity in the ' $y$ ' direction with the mean velocity approximately 15\% higher downstream of the outside of the corner. This is caused by the turning effect of the screen, a well-documented phenomenon which has been used advantageously in other experiments 7 to generate mean velocity profiles with a desired shape. It is based on the observation that if the flow into the screen is at an angle other than $90^{\circ}$, the flow tends to leave at an angle closer to $90^{\circ}$. In this case, the turning due to the screen counteracts the effects of the turning vanes, resulting in a non-zero velocity component towards the outside of the corner. The shear flow generated persists for all downstream distances, and if this scheme is used in a full-scale facility, it would certainly be present in the test section. As a result, the $45^{\circ}$ screen alone, either immediately or some distance downstream of the turning vanes, is not suitable as a turbulence manipulator due to these effects on the mean flow. It does however, reduce the turbulence level somewhat from that existing in the tunnel without the screen. The extent of this effect will be discussed in more detail later in this chapter. As stated above, the main purpose of the screen is to use it in combination with the honeycomb, and these results are presented in the next section.

$45^{\circ}$ Honeycomb and $45^{\circ}$ Screen

Several honeycombs were constructed based on the "new concept," where the honeycomb can be mounted up against the turning vanes, at $45^{\circ}$ to the mean flow, yet with the cells aligned with the flow direction. Three mesh sizes were used, $1.56,3.13$ and 6.25 $\mathrm{mm}$, with the honeycombs having a length/cell diameter ratio of 16, 10 and 10, respectively. Further construction details are found in the section on the flow manipulators. 
Selecting the $3.13 \mathrm{~mm}$ mesh $45^{\circ}$ honeycomb, which is optimally scaled with the screen, the effectiveness of the honeycomb and honeycomb-screen combination was documented with the honeycomb positioned at the downstream end of the turning vanes, i.e., $\Delta x=0$ in Figure 1. There are several important characteristics of the flow apparent from the mean velocity and turbulence intensity profiles presented in Figure 7. Considering the mean velocity first, the wake from each turning vane is clearly visible at the probe position $x=21.6 \mathrm{~cm}$, both with and without the screen. These wake defects are noticeably smaller when the screen is present at the downstream end of the honeycomb. An encouraging observation is that there is hardly any evidence of the mean shear noticed in Figure 6 . Both of these results suggest that the $45^{\circ}$ screen can be effectively used with the $45^{\circ}$ honeycomb. The turbulence intensity profiles indicate that the screen contributes to reducing and uniformizing the turbulence level although there is still a large amount of spatial variation. Based on these observations, all subsequent results in this chapter will be presented for the $45^{\circ}$ honeycomb in combination with a $45^{\circ}$ screen positioned next to the downstream end of the honeycomb.

A disturbing character of these data is the apparent persistence of the wake defects in the mean velocity and the large spatial variations in the turbulence intensity, especially in comparison to Figure 3. The peaks correspond to the shear layers of the turning vanes, and are obvious even at the probe location $x=21.6$ $\mathrm{cm}$. To determine the extent of this persistence, the results at $\mathrm{x}=21.6 \mathrm{~cm}$ are compared to those at $\mathrm{x}=40.6 \mathrm{~cm}$ in Figure 8. Even at large distances from the turning vanes, $\mathbf{x}=40.6$ $\mathrm{cm}$, each wake defect is clearly visible in the mean velocity profile, although all of them are not quite as large as at $\mathrm{x}=21.6$ $\mathrm{cm}$. The turbulence intensity profile is still quite nonuniform even at this large distance, due to the presence of the shear regions in the mean flow. The increase in rms near the walls is due to the growth of the boundary layer on the wall of the duct. Obviously the nonuniformity caused by the turning vanes lasts for large distances when the $45^{\circ}$ honeycomb and screen

14. 
combination is positioned at the downstream end of the turning vanes. Recall from Figure 3 that the wake defects decay rapidly with downstream distance when there is no flow manipulator in the duct. Even with the conventional honeycomb-screen combination in the duct, there was no evidence of the turning vane wakes; see Figures 4 and 5 . The wake mixing mechanism present in those cases has been inhibited or eliminated by the presence of the $45^{\circ}$ honeycomb. It was also determined in the discussion of Figures 4 and 5 that higher upstream turbulence led to better spatial uniformity of the flow characteristics downstream of the turning vanes. It is hypothesized that the turbulence that was available for mixing the wakes of the turning vanes, both in the mean flow and in the vane shear layers, has been removed by the $45^{\circ}$ honeycomb before it was able to have an effect. The turbulence subsequently generated by the $45^{\circ}$ honeycomb-45 $5^{\circ}$ screen combination is at the wrong scale, probably too small, to have any significant effect on these large scale mean velocity nonuniformities. To establish whether or not this was true, and to determine if there was an effective way to correct the problem, the following experiments were conducted.

Effect of Separation Between Turning Vanes and $45^{\circ}$ Honeycomb

If the honeycomb removed turbulence from the flow which was of a scale suitable for the wake mixing, some separation between the turning vanes and the upstream end of the honeycomb, $\Delta x$, should give the existing turbulence a chance to mix the wakes before the honeycomb removes it and generates its own turbulence of a different scale. Figure 9 shows the mean velocity and turbulence intensity profiles for three separations, $\Delta x$ equals $0,2.5$, and $5.0 \mathrm{~cm}$. Recall that the spacing between the turning vanes is about $2.5 \mathrm{~cm}$ as well.

The effect of providing some decay time for the wakes to merge before they enter the $45^{\circ}$ honeycomb $-45^{\circ}$ screen combination is quite clear, with the spatial uniformity in mean velocity improving as the separation increases. At a separation $\Delta \mathbf{x}=5.0 \mathrm{~cm}$, the uniformity is about as good as that downstream of the conventional 
honeycomb and screen as shown in Figure 4. A similar improvement is noted in the turbulence intensity profiles, particularly between the cases $\Delta x=0$ and $\Delta x=2.5 \mathrm{~cm}$. However, with an increase in $\Delta x$, the honeycomb becomes closer to the probe since the probe position is fixed at $x=21.6 \mathrm{~cm}$; see Figure 1 . In spite of the shorter decay distance as $\Delta x$ increases, the average turbulence intensity is decreasing.

This result not only substantiates our hypothesis on the importance of the turbulence generated by the turning vanes in initially uniformizing the mean velocity and turbulence intensity, but also indicates one possible solution to the problem of the persistent wake defect when using the $45^{\circ}$ honeycomb $-45^{\circ}$ screen combination. The feasibility of using separation depends on the design of the tunnel, as a $\Delta x$ of 2 vane spacings is apparently adequate to provide sufficient uniformity.

Effect of $45^{\circ}$ Honeycomb Mesh Size

Another variable of importance is the mesh size of the honeycomb, as this determines the dominant generated-turbulence scales. The relationship between the scales for each turbulence generating device influences the overall performance. On Figures 10 and 11 are shown the mean velocity and turbulence intensity profiles obtained using the three different honeycomb mesh sizes, 1.56, 3.13 and $6.25 \mathrm{~mm}$, at two separations, $\Delta x=0$ and $\Delta x=5.0 \mathrm{~cm}$. Concentrating first on the results for $\Delta x=0$, increasing the honeycomb mesh size decreases the magnitude of the wake defects from the turning vanes. This is due to the larger-mesh honeycomb generating larger scales that are better suited for effectively mixing the wakes. However, the spatial uniformity of the mean velocity is still not as good as that which can be obtained using separation between the honeycomb and the turning vanes, as shown in Figure 9. The turbulence level is also highest downstream of the $6.25 \mathrm{~mm}$ mesh honeycomb. This is partly because the downstrcam end of the longer larger-mesh honeycombs is closer to the probe position, $\mathrm{x}=21.6 \mathrm{~cm}$, and partly because the turbulence reduction is not as effective with the larger honeycomb, due to

16. 
the generated turbulence characteristics. The same $45^{\circ}$ screen was also used with all three honeycombs, and previous work has shown that there is an optimum mesh ratio between the screen and honeycomb of 3 or 4 to 1, (see Ref. 2). The screen used for these experiments matches the 1.56 and $3.13 \mathrm{~mm}$ mesh honeycombs better. One other detrimental effect of the larger mesh honeycomb is that there is substantially more mean shear generated by the turning action of the screen, as described in detail for Figure 6. Presumably this would not be the case if the screen mesh was appropriately scaled for the larger mesh honeycomb to optimize the blockage for each cell while generating turbulence of appropriate scale for overcoming the honeycomb generated turbulence.

Considering the case with separation, $\Delta \mathbf{x}=5.0 \mathrm{~cm}$, the mean velocity profiles again demonstrate the importance of allowing some distance for the turning-vane wakes to mix. The spatial uniformity in both cases is about as good as that obtained for the conventional honeycomb, although there is slightly more mean shear present for the $3.13 \mathrm{~mm}$ mesh honeycomb due to the turning effect of the screen. There is a much more significant difference in the turbulence intensity, being quite low for the $1.56 \mathrm{~mm}$ mesh honeycomb, and being much more spatially uniform for both mesh sizes as compared with the results for $\Delta \mathrm{x}=0$. However, the pressure drop associated with the $1.56 \mathrm{~mm}$ mesh honeycomb is high, and usually does not lead to the most efficient way of improving the turbulence.

The mesh size is therefore quite important, especially if the honeycomb is to be mounted along the turning-vanes trailing edges. The mesh of the honeycomb must be properly scaled to the turning vanes so that the wakes mix quickly. However, the turbulence reduction effectiveness is usually lessened. With some separation, the honeycomb mesh can be selected based on the free-stream turbulence characteristics, much in the same way as for conventional honeycombs ${ }^{2}$, with significant improvement in the efficiency of the turbulence reducing flow manipulators.

17. 
Before discussing the relative effects of the methods for reducing the turbulence, one more parameter was investigated for the "new-concept" honeycomb. As is the case for using any type of flow manipulator, a very desirable, almost necessary, characteristic is that the turbulence reduction should be independent of free-stream velocity.

Effect of Free-Stream Velocity on $45^{\circ}$ Honeycomb Performance

The data with the $3.13 \mathrm{~mm}$ mesh $45^{\circ}$ honeycomb-45 combination downstream of the turning vanes, $\Delta \mathbf{x}=5.0 \mathrm{~cm}$, for three different free-stream velocities, 20.4, 27.6 and 36 meters per second, are plotted on Figure 12. Both the mean velocity and turbulence intensity profiles are reasonably independent of free-stream velocity, both in spatial uniformity and in turbulence intensity magnitude. This demonstrates that the use of the $45^{\circ}$ honeycomb and $45^{\circ}$ screen .combination with a separation $\Delta x=5.0 \mathrm{~cm}$ from the turning vanes results in the flow characteristics downstream being independent of free-stream velocity, and certainly strengthens the possibilities of using such a combination for turbulence control.

Relative Effectiveness of Different Types of Turbulence Manipulators

In order to make a final evaluation of the "new-concept" honeycomb, a direct comparison with the conventional honeycomb as well as with other flow manipulators is necessary. The flow characteristics downstream of the "new-concept" $45^{\circ}$ honeycomb-45 screen combination, the turning vanes when there is no manipulator present, a $45^{\circ}$ screen at the turning vanes trailing edge, and a conventional honeycomb-screen combination, are presented in Figures 13-16 for both low and high upstream turbulence. Concentrating first on the results for low upstream turbulence, Figures 13 and 14 , one notes that the conventional honeycomb and screen combination provides the best spatial uniformity of the

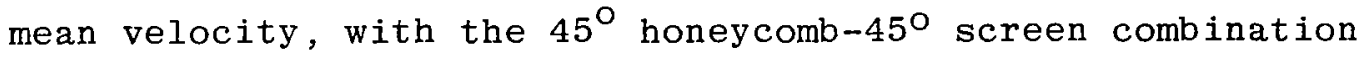
slightly worse, but not much different from the case with no manipulator in the duct. The $45^{\circ}$ screen alone provides the worst

18. 
performance, which was explained previously with the aid of Figure 6. Reviewing the turbulence intensity profiles of Figure 14 , the $45^{\circ}$ honeycomb $-45^{\circ}$ screen results in the lowest overall turbulence intensity, although it is less spatially uniform than the turbulence intensity downstream of the conventional honeycomb and screen combination. There is a greater turbulence intensity at the same downstream location for both the $45^{\circ}$ screen and the turning vanes alone, with the $45^{\circ}$ screen being lower. However, all of these results are for low upstream turbulence and as was noted before, higher upstream turbulence permits better mixing of the turning-vane wakes for more spatially uniform flow characteristics, and is also a more realistic condition for most wind tunnels.

The effects of higher upstream turbulence are demonstrated for any manipulator by comparing the corresponding profiles in Figures 13 and 15. There is a substantial improvement in the mean velocity spatial uniformity in all cases, with greater improvement for the $45^{\circ}$ honeycomb $-45^{\circ}$ screen combination and the $45^{\circ}$ screen alone. As a result, the flow downstream of the $45^{\circ}$ honeycomb $-45^{\circ}$ screen combination is now comparable to that obtained with the conventional honeycomb and screen combination. A similar effect is observed for the turbulence intensity, Figure 16, for these flow-manipulator combinations. Again, there is a greater improvement in the uniformity of the flow downstream of the $45^{\circ}$ honeycomb $-45^{\circ}$ screen combination due to the higher upstream turbulence as compared to the conventional honeycomb screen combination; see Figures 14 and 16. Interestingly, there is no appreciable change in the turbulence intensity at the probe position with the much higher upstream turbulence, indicating that both of the honeycomb flow manipulators are at least properly controling the turbulence.

In summary, the overall flow characteristics downstream of the $45^{\circ}$ honeycomb $-45^{\circ}$ screen combination are comparable to those present downstream of the conventional honeycomb and screen combination, especially for higher upstream turbulence, when the manipulator combination is positioned and scaled correctly. 
A single $45^{\circ}$ screen along the downstream edges of the turning vanes proyides inferior performance, in some respects even worse than with no manipulator downstream of the turning vanes at all. Therefore, the screen above should not be recommended as a logical choice for improving mean velocity and turbulence level in the settling chamber of any wind tunnel.

\section{$\underline{\text { Summary }}$}

In order to attach some overall quantitative significance to the results of Figures $3-16$ and to have some measure of the relative performance of each manipulator, the effect on the turbulence intensity for each of the manipulator combinations and their relative positions is compiled in Table 1 . In the table, under the heading $u^{\prime} / U_{\infty}$, the turbulence intensity, the numbers in parentheses are approximate maximum and minimum values of the turbulence intensity across the test section, while the third number is a realistic spatial average. It should be noted that the maximum levels occur near the inside corner and may be artificially high due to the sidewall boundary layer or to some separated region at the inside corner. The quantity $F_{1}{ }^{*}$ is defined as the ratio of the turbulence intensity downstream of the turning vanes alone to the turbulence intensity at the same downstream position when a flow manipulator is used. The higher the value of $F_{1}{ }^{*}$, the more effective the flow manipulator is at reducing the turbulence. At large downstream distances, i.e. long decay time, turbulence reductions of approximately $2 \mathrm{~F}_{1}{ }^{*}$ may be expected.

While all of the values reflect the observations discussed in connection with the appropriate figures, a quantitative comparison of the most promising manipulator combinations is useful. As in the foregoing discussion, the performance level of the $3.13 \mathrm{~mm}$ mesh conventional honeycomb and screen combination is used as the standard. With respect to this standard, the $3.13 \mathrm{~mm}$ mesh $45^{\circ}$ honeycomb $-45^{\circ}$ screen combination, $\Delta \mathrm{x}=$ $5.0 \mathrm{~cm}$, provides slightly better ( $5 \%$ to $10 \%$ ) overall turbulence reduction for both low and high upstream turbulence, although 
Table 1. Comparison of Manipulator Performance

\begin{tabular}{|c|c|c|c|c|c|c|c|}
\hline \multirow{3}{*}{$\begin{array}{l}\text { MANIPULATOR } \\
\text { Turning Vanes Alone }\end{array}$} & \multirow[b]{2}{*}{$\mathrm{U}_{\infty}(\mathrm{m} / \mathrm{sec})$} & \multicolumn{3}{|c|}{ LOW UPSTREAM TURB. } & \multicolumn{3}{|c|}{ HIGH UPSTREAM TURB. } \\
\hline & & $u^{\prime} / U_{0}$ & & $\mathrm{~F}_{1}{ }^{\star}$ & $u^{2} / U_{0}$ & $(\%)$ & $\mathrm{F}_{1}{ }^{*}$ \\
\hline & $\approx 30$ & 3.6 & $\left(\begin{array}{l}4.74 \\
2.44\end{array}\right)$ & 1 & 3.8 & $\left(\begin{array}{l}4.98 \\
3.0\end{array}\right)$ & 1 \\
\hline $45^{\circ}$ Screen, $\Delta x=0$ & " & 2.43 & $\left(\begin{array}{l}2.91 \\
1.93\end{array}\right)$ & 1.48 & 2.59 & $\left(\begin{array}{l}5.06 \\
2.15\end{array}\right)$ & 1.47 \\
\hline $\begin{array}{l}3.13 \mathrm{~mm} \text { Mesh Conventional } \\
\text { Honeycomb and Screen }\end{array}$ & $"$ & 1.58 & $\left(\begin{array}{l}2.02 \\
1.14\end{array}\right)$ & 2.28 & 1.58 & $\left(\begin{array}{l}1.86 \\
1.26\end{array}\right)$ & 2.41 \\
\hline $\begin{array}{l}3.13 \mathrm{~mm} \text { Mesh } 45^{\circ} \text { Honeycomb } \\
+45^{\circ} \text { Screen, } \Delta x=5.0 \mathrm{~cm}\end{array}$ & $"$ & 1.47 & $\left(\begin{array}{l}2.28 \\
0.82\end{array}\right)$ & 2.45 & 1.39 & $\left(\begin{array}{l}2.46 \\
1.11\end{array}\right)$ & 2.73 \\
\hline $\begin{array}{l}3.13 \mathrm{~mm} \text { Mesh } 45^{\circ} \text { Honeycomb } \\
+45^{\circ} \text { Screen, } \Delta x=2.5 \mathrm{~cm}\end{array}$ & $"$ & & & & 2.02 & $\left(\begin{array}{l}2.97 \\
1.14\end{array}\right)$ & 1.88 \\
\hline $\begin{array}{l}3.13 \mathrm{~mm} \text { Mesh } 45^{\circ} \text { Honeycomb } \\
\Delta x=2.5 \mathrm{~cm}\end{array}$ & $"$ & 2.53 & $\left(\begin{array}{l}4.01 \\
1.3 .\end{array}\right)$ & 1.42 & & & \\
\hline $\begin{array}{l}3.13 \mathrm{~mm} \text { Mesh } 45^{\circ} \text { Honeycomb } \\
+45^{\circ} \text { Screen, } \Delta x=0\end{array}$ & .11 & 1.74 & $\left(\begin{array}{l}2.83 \\
0.64\end{array}\right)$ & 2.47 & 1.71 & $\left(\begin{array}{l}2.78 \\
1.14\end{array}\right)$ & $2.2 i$ \\
\hline $\begin{array}{l}3.13 \mathrm{~mm} \text { Mesh } 45^{\circ} \text { Honeycomb } \\
\Delta \mathrm{x}=0\end{array}$ & $"$ & 2.34 & $\left(\begin{array}{l}3.75 \\
0.96\end{array}\right)$ & 1.54 & & & \\
\hline $\begin{array}{l}1.56 \mathrm{~mm} \text { Mesh } 45^{\circ} \text { Honeycomb } \\
+45^{\circ} \text { Screen, } \Delta x=5.0 \mathrm{~cm} \\
\end{array}$ & $"$ & & & & 1.09 & $\left(\begin{array}{l}1.76 \\
0.73\end{array}\right)$ & 3.49 \\
\hline $\begin{array}{l}1.56 \mathrm{~mm} \text { Mesh } 45^{\circ} \text { Honeycomb } \\
+45^{\circ} \text { Screen, } \Delta x=0\end{array}$ & $"$ & & & & 2.15 & $\left(\begin{array}{l}3.41 \\
1.20\end{array}\right)$ & 1.77 \\
\hline $\begin{array}{l}6.25 \mathrm{~mm} \text { Mesh } 45^{\circ} \text { Honeycomb } \\
+45^{\circ} \text { Screen, } \Delta x=0\end{array}$ & $"$ & & & & 2.21 & $\left(\begin{array}{l}4.02 \\
1.42\end{array}\right)$ & 1.72 \\
\hline $\begin{array}{l}6.25 \text { min Mesh } 45^{\circ} \text { Honeycomb } \\
\Delta x=0\end{array}$ & $"$ & 2.78 & $\left(\begin{array}{l}4.36 \\
1.67\end{array}\right)$ & 1.29 & & & \\
\hline $\begin{array}{l}3.13 \mathrm{~mm} \text { Mesh } 45^{\circ} \text { Honeycomb } \\
+45^{\circ} \text { Screen, } \Delta x=5.0 \mathrm{~cm}\end{array}$ & $\approx 20.4$ & & & & 1.77 & $\left(\begin{array}{l}2.83 \\
1.35\end{array}\right)$ & 2.15 \\
\hline $\begin{array}{l}3.13 \mathrm{~mm} \text { Mesh } 45^{\circ} \text { Honeycomb } \\
+45^{\circ} \text { Screen, } \Delta \mathrm{x}=0\end{array}$ & $\approx 20.4$ & & & & 2.04 & $\left(\begin{array}{l}3.44 \\
1.39\end{array}\right)$ & 1.86 \\
\hline $\begin{array}{l}3.13 \mathrm{~mm} \text { Mesh } 45^{\circ} \text { Honeycomb } \\
+45^{\circ} \mathrm{Screen}, \Delta \mathrm{x}=5.0 \mathrm{~cm}\end{array}$ & $\approx 36.0$ & & & & 1.40 & $\left(\begin{array}{l}2.95 \\
1.00\end{array}\right)$ & 2.71 \\
\hline
\end{tabular}

1. Screen mesh is $0.91 \mathrm{~mm}$ in all cases

2. $F_{1} *=\frac{\left(u^{\prime} / U_{\infty}\right)}{\left(u^{\prime} / U_{\infty}\right)}$ marning vanes alone values of ( $\left(u^{\prime} / U_{\infty}\right)$ in parenthese values in the $y$-direction 
there is a larger difference between the maximum and minimum turbulence intensity leyels. This is a reflection of the somewhat higher spatial nonuniformity as observed in Figures 14 and 16. The other manipulator combinations which do as well as, or better than, the conventional honeycomb and screen combination can also be easily selected from this table. However, the values quoted in the table should always be used in connection with the appropriate figures and discussion before making any conclusions. 


\section{CONCLUSION}

Based on the results of this investigation and the discussion of the previous section, the following conclusions on the operation of wind tunnel turning vanes and on using the "new-concept" honeycomb in conjunction with these turning vanes can be stated:

I. Higher turbulence upstream of the turning vanes (even a very small increase in turbulence intensity) yields better spatial uniformity of the mean flow and turbulence intensity downstream of the turning vanes, both with and without flow manipulators.

2. Upstream swirl is almost completely eliminated by the turning vanes, even though the swirl has a strong concentrated vortex. The flow manipulators downstream of the turning vanes do not have to be designed to remove such swirls.

3. A single screen stretched across the trailing edges of the turning vanes leads to conditions that are inferior to those present when using the turning vanes alone. Either a conventional honeycomb and screen combination or the "new-concept" $45^{\circ}$ honeycomb- $45^{\circ}$ screen combination would, therefore, offer much better solutions. The addition of a single screen immediately downstream of the honeycomb significantly improves the performance for all honeycombs, especially where the mean velocity is reasonably uniform upstream of the honeycomb.

4. Proper turbulence management solutions, using either the conventional honeycomb and screen combination or the "new-concept" $45^{\circ}$ honeycomb- $45^{\circ}$ screen combination, result in overall flow characteristics essentially independent of conditions upstream of the turning vanes. However, spatial uniformity is affected by the upstream conditions, (see conclusion 1 ).

5. The "new-concept" $45^{\circ}$ honeycomb-45" screen combination with adequate separation from the turning vanes (approximately 2 vane meshes) results in mean flow 
conditions and turbulence intensity levels comparable to those produced by a conventional honeycomb and screen combination.

6. Separation between the turning vanes and the $45^{\circ}$ honeycomb $-45^{\circ}$ screen combination leads to improved performance by allowing the vane wakes some distance to mix and decay under the influence of their own generated turbulence. Eliminating the separation distance and placing the honeycomb too close to the turning vanes removes the turbulence necessary for efficient wake mixing too soon, resulting in persistent mean velocity wake defects for large distances downstream. Adequate separation distance is approximately 2 vane meshes and is made shorter by higher upstream turbulence and honeycomb pressure drop.

7. Using no separation between the turning vanes and the $45^{\circ}$ honeycomb $-45^{\circ}$ screen combination renders the concept less effective due to the lack of turning vane wake decay, as described in conclusion 6, resulting in large spatial nonuniformities and slower turbulence decay. The honeycomb mesh must be scaled to the turningvanes mesh when no separation is used (mesh ratio of about 5) to improve spatial uniformity, instead of being scaled to the turbulence characteristics for maximum turbulence reduction.

8. Proper selection of the honeycomb-screen combination downstream of the turning vanes could lead to a reduction in turbulence by a factor of almost 7 ahead of the contraction and a factor of more than 10 after the contraction.

As stated above, the "new concept" honeycomb and screen can be used in place of the conventional honeycomb and screen with some improvement in the turbulence reduction, if some separation is provided between the turning vanes and the honeycomb. However, in the Introduction, it was theorized that by acting on the turbulence sooner, the turbulence intensity at any position

24. 
downstream should be much lower. The turbulence is also at a later stage of decay, indicating larger scales of the turbulence. Considering the slightly better turbulence reduction using the "new concept" $45^{\circ}$ honeycomb $-45^{\circ}$ screen combination, the real proof of whether or not it is significantly better will depend on the contraction effects on the two turbulent flows of approximately the same turbulence intensity but of different scales. Unfortunately, this question cannot be answered at present, as no study of this effect has been performed to date. Once this information is known, it will then be possible to decide whether the extra expense incurred for fabricating and installing the "new-concept" honeycomb will be justified. 


\section{REFERENCES}

1. Loehrke, R. I. and Nagib, H. M. , "Experiments on Management of Free Stream Turbulence," AGARD Report No. 598, 1972; also available from NTIS as $A D-749-891$.

2. Loehrke, R. I. and Nagib, H. M., "Control of Free Stream Turbulence by Means of Honeycombs: A Balance Between Suppression and Generation," ASME Paper 76-FE-2; J. Fluids Eng., Trans. ASME, Vol. 98, No. 3, 1976.

3. Tan-atichat, J., Nagib, H. M. and Loehrke, R. I., "Interaction of Free Stream Turbulence with Screens and Perforated Plates: A Balance Between Turbulence Scales," Submitted to J. Fluids Eng., Trans. ASME.

4. Ahmed, M., Wigeland, R. A. and Nagib, H. M., "Generation and Management of Swirling Flows in Confined Streams," I.I.T. Fluids and Heat Transfer Report R76-2; Interim Technical Report, ARO-ITR-76 - 1, 1976.

5. Ahmed, M., Wigeland, R. A. and Nagib, H. M., "Generation, Management and Suppression of Large Scale Vorticity in Internal Flows," Proceedings of the SQUID Workshop on Turbulence in Internal Flows, Washington, D.C., 1976, Plenum Publishing Corporation, 1977.

6. Wigeland, R. A., Ahmed, M. and Nagib, H. M., "Management of Swirling Flows with Application to Wind-Tunnel Design and V/STOL Testing," AIAA Paper No. 77-585, AIAA/NASA Ames V/STOL Conference, Moffett Field, California, June, 1977; also AIAA Journal, Vol. 16, No. 11, November 1978, Page 1125.

7. Laws, E. M. and Livesey, J. L., "Flow Through Screens," Ann. Rev. Fluid Mech., 10, 1978, p.247. 


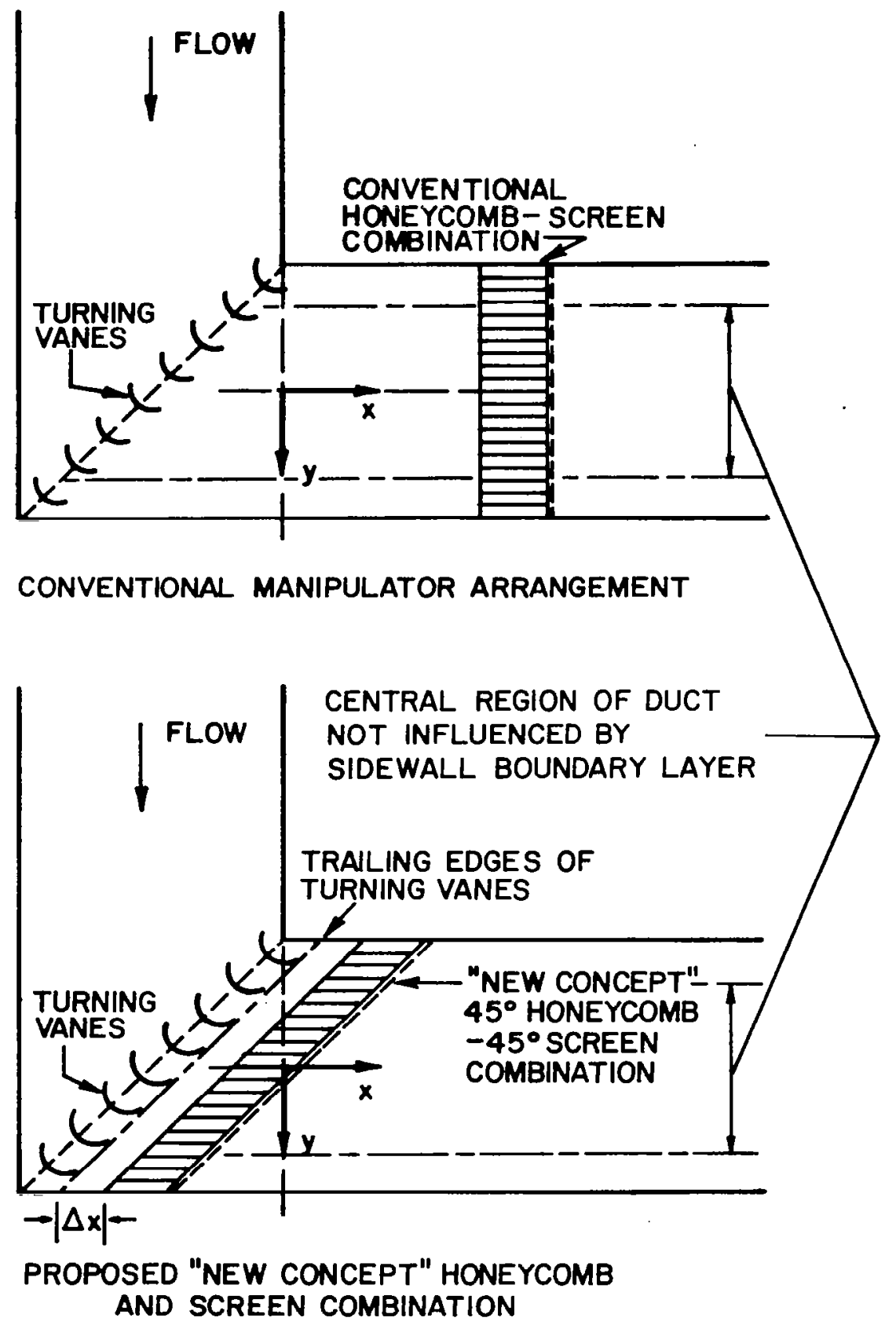

Figure 1. Schematic of proposed "new-concept" $45^{\circ}$ honeycomb and comparison with a conventional honeycomb 

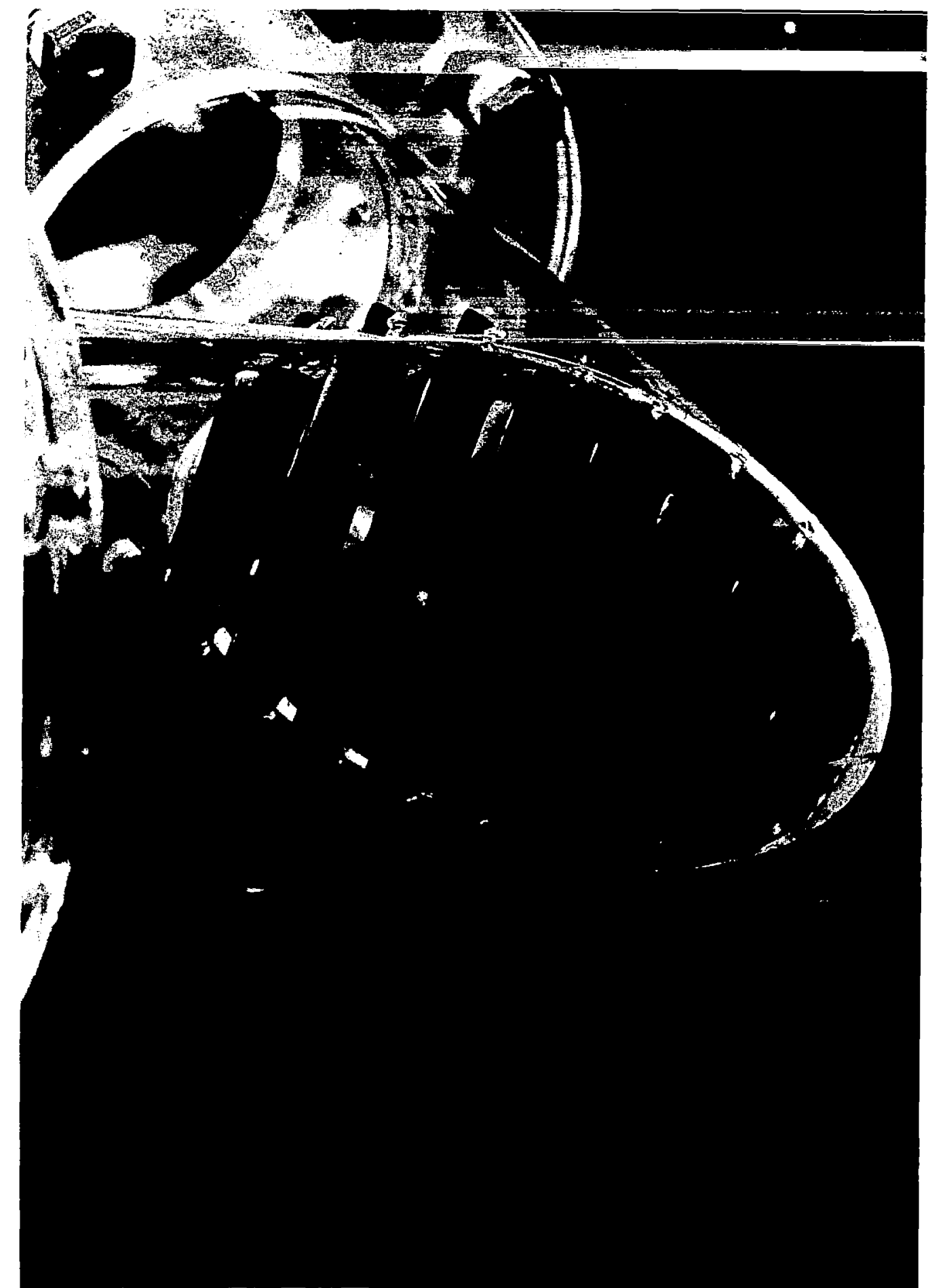

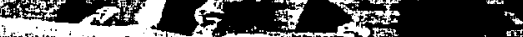

Figure 2 . Photograph of scale-model turning vanes mounted in a 28. 


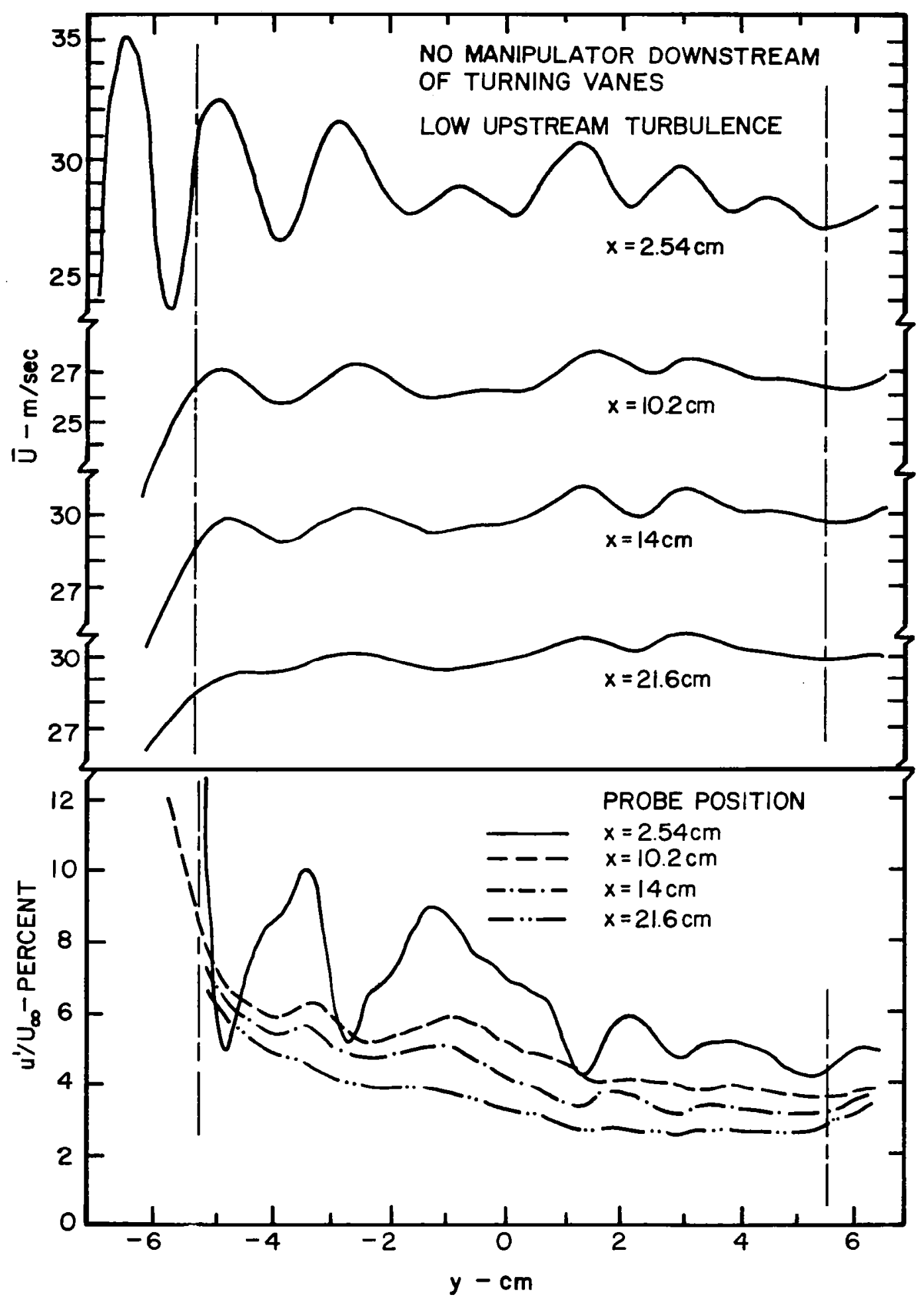

Figure 3. Lateral profiles of mean velocity and turbulence intensity at several distances downstream of turning vanes with low upstream turbulence 


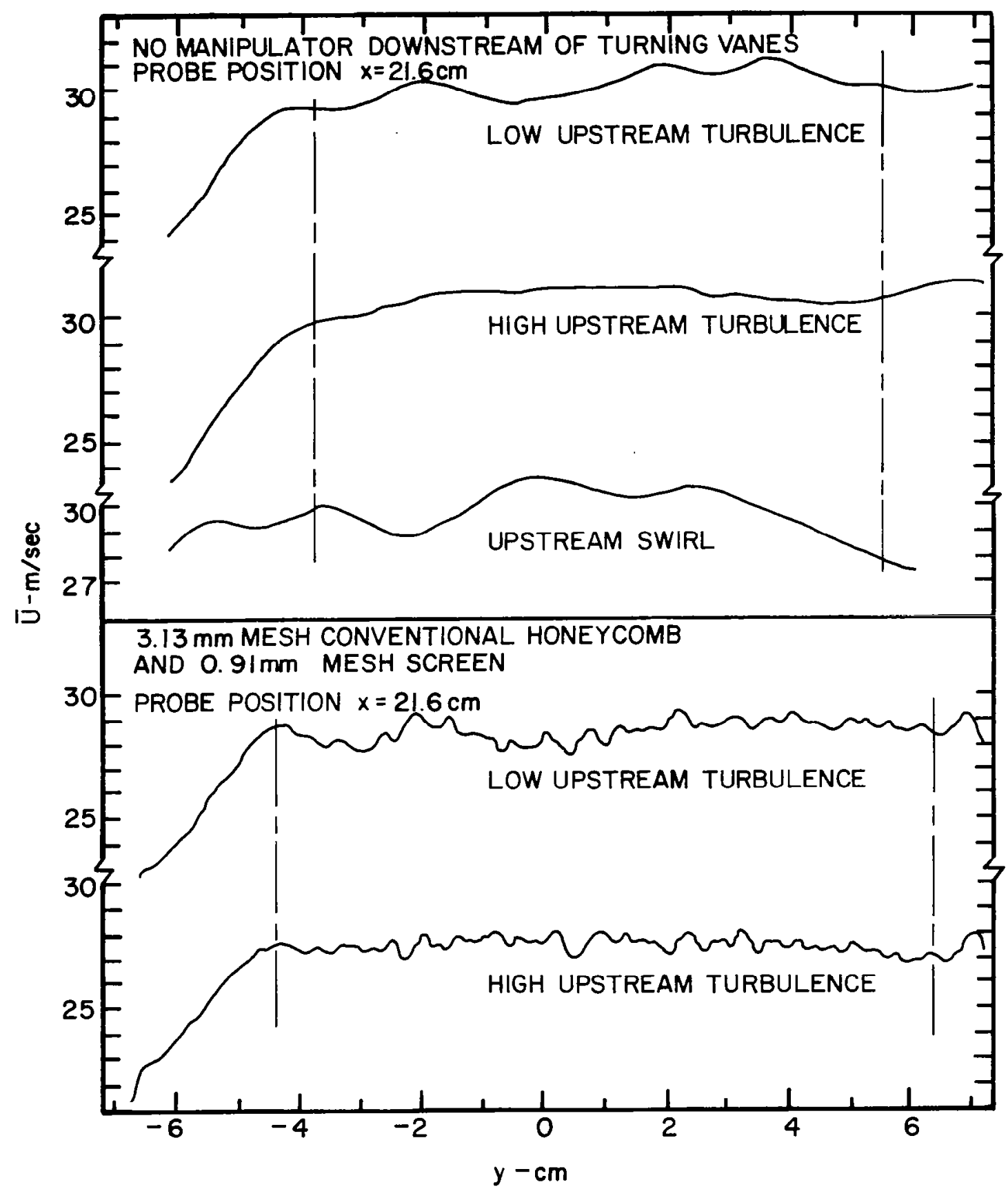

Figure 4. Lateral profiles of mean velocity with either a conventional honeycomb or no flow manipulator downstream of turning vanes in several flow conditions 


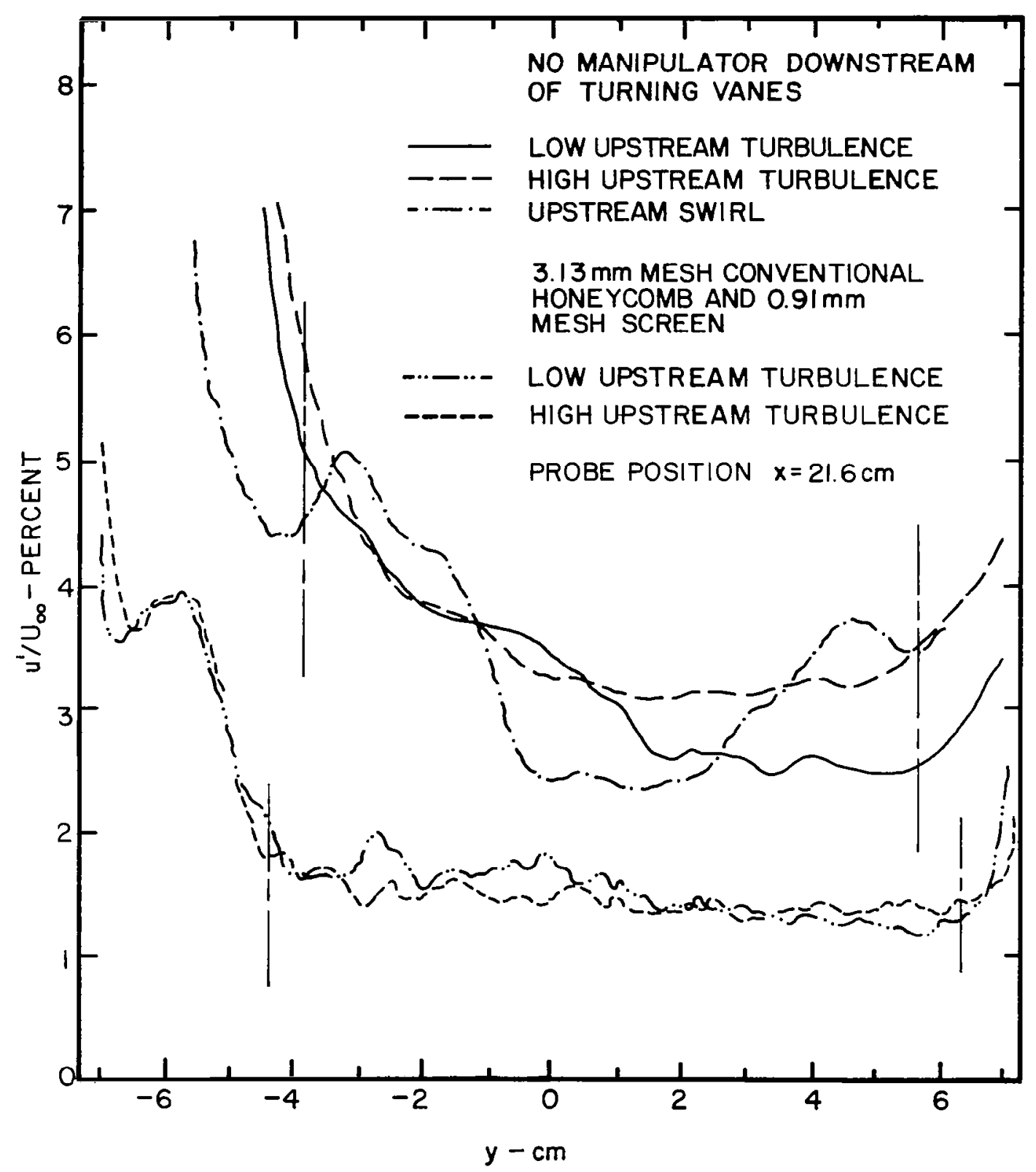

Figure 5. Lateral profiles of turbulence intensity with either a conventional honeycomb or no flow manipulator downstream of turning vanes in several flow conditions 


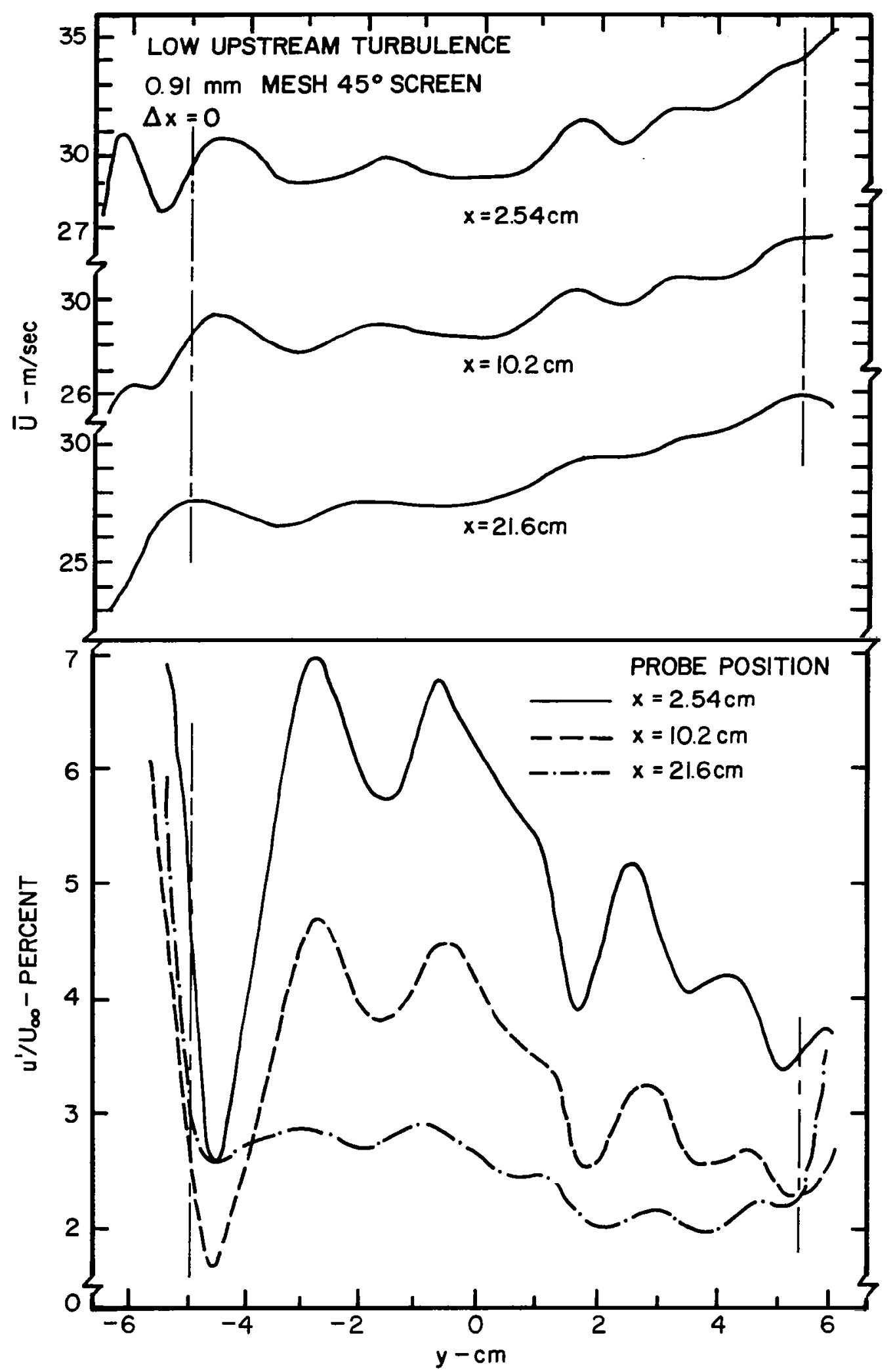

Figure 6. Lateral profiles of mean velocity and turbulence intensity at several distances downstream of turning vanes with a $0.91 \mathrm{~mm}$ mesh $45^{\circ}$-screen positioned at trailing edges of turning vanes in low turbulence flow condition 


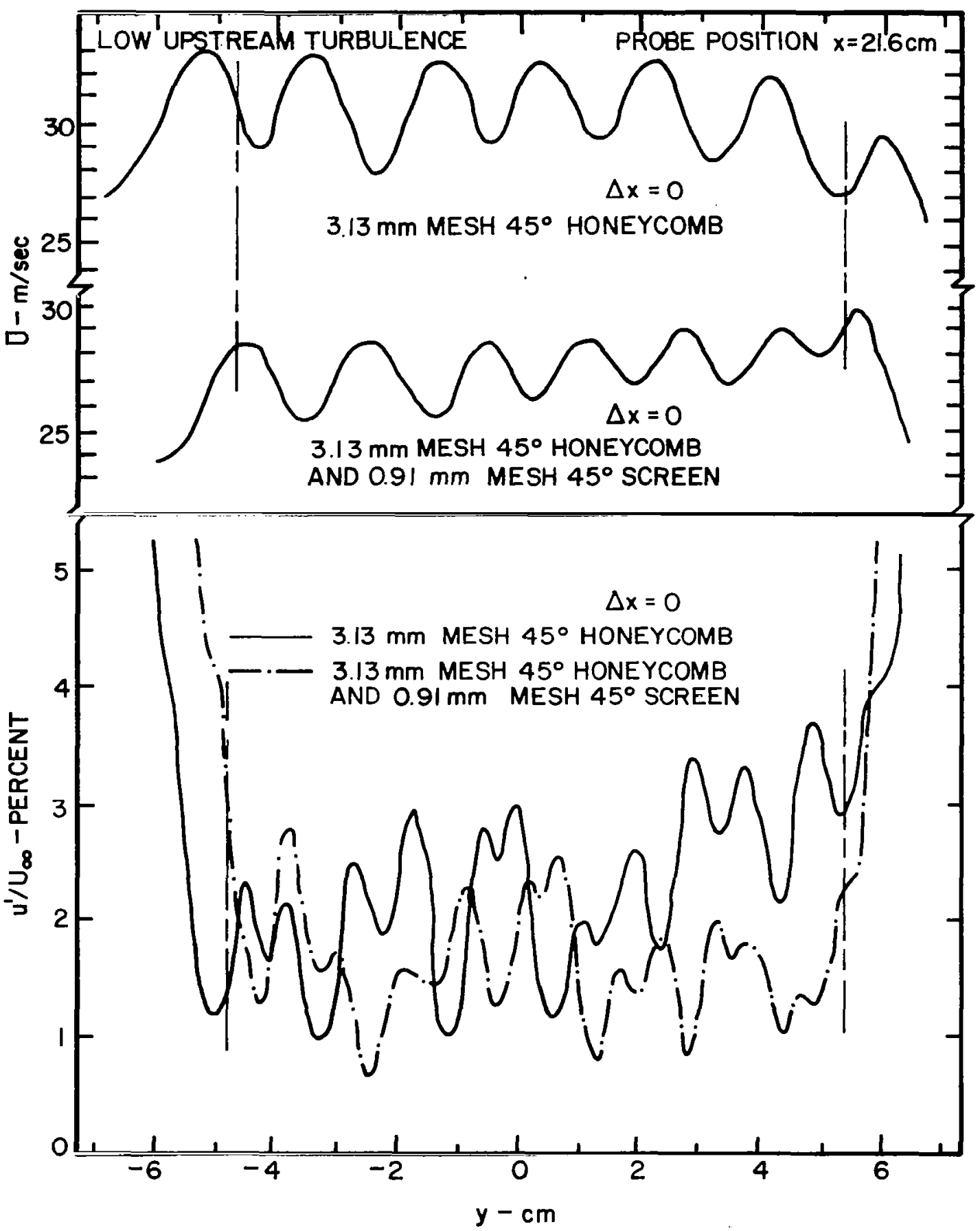

Figure 7. Lateral profiles of mean velocity and turbulence intensity with a $3.13 \mathrm{~mm}$ mesh $45^{\circ}$-honeycomb positioned at trailing edges of turning vanes with and without a $0.91 \mathrm{~mm}$ mesh $45^{\circ}$-screen at downstream end of honeycomb in low turbulence flow condition 


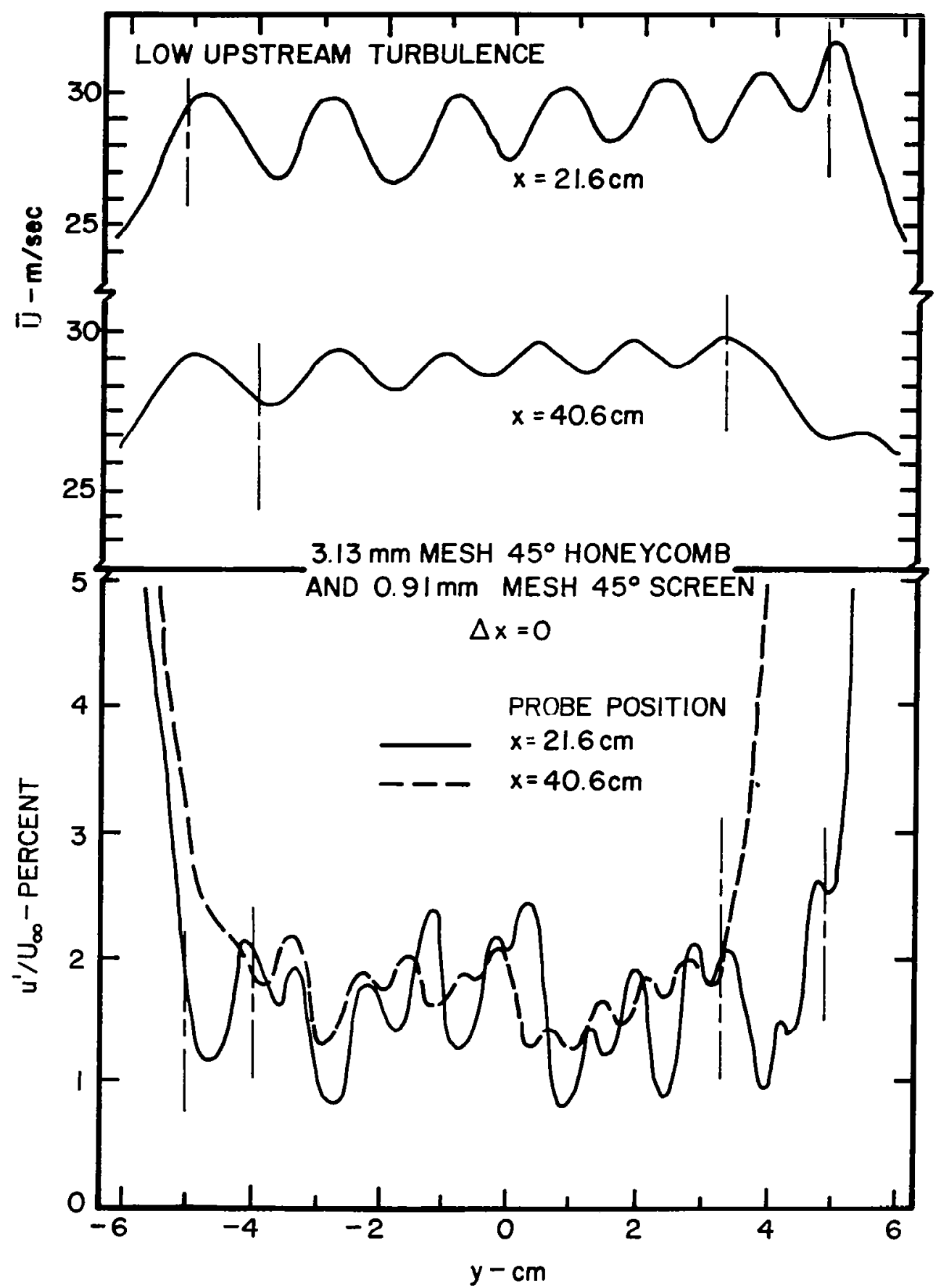

Figure 8. Lateral profiles of mean velocity and turbulence intensity for two distances downstream of turning vanes with a $45^{\circ}$ honeycomb$45^{\circ}$-screen positioned at trailing edges of turning vanes in low turbulence flow condition 


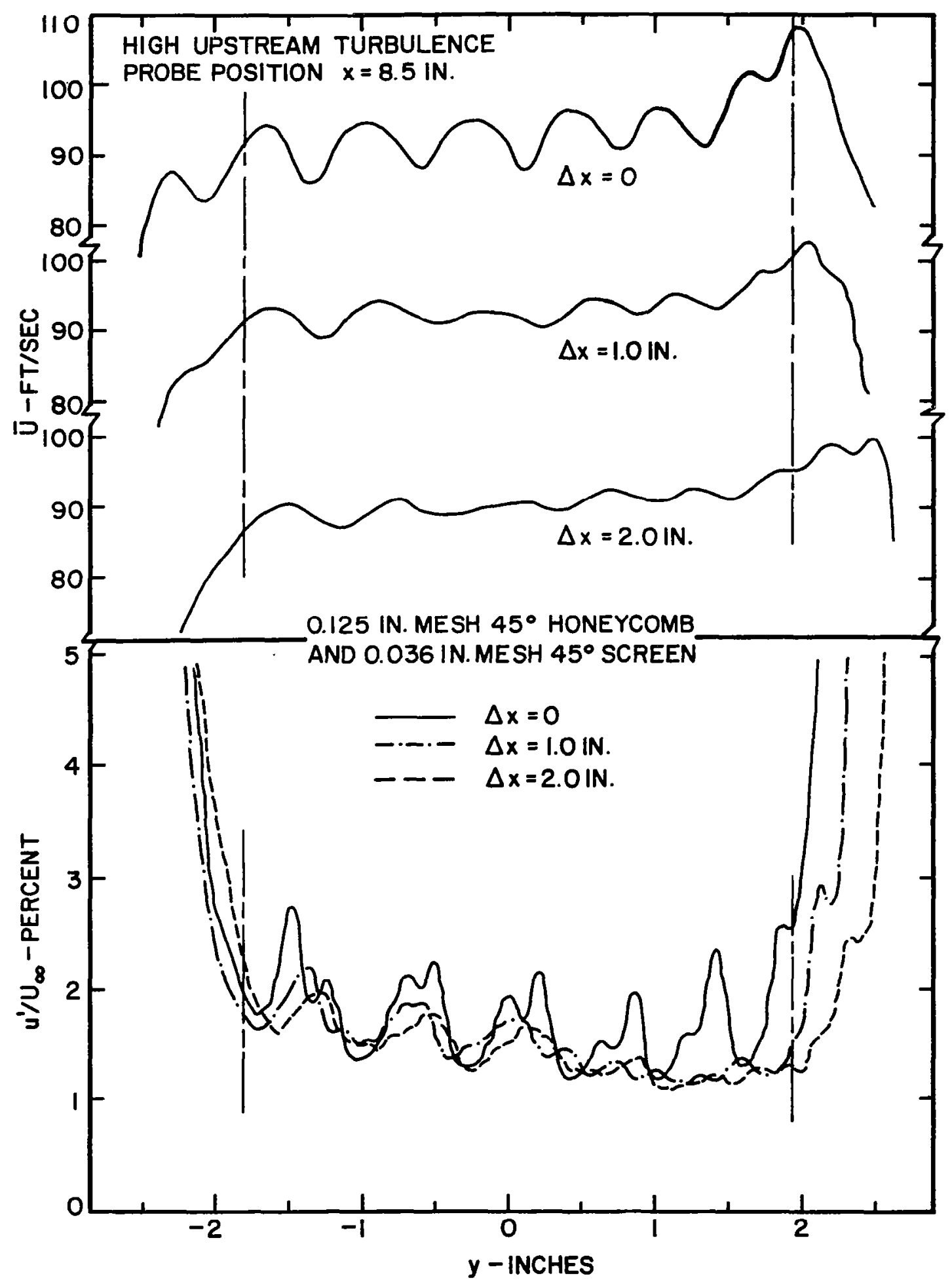

Figure 9. Effect of separation between $45^{\circ}$ honeycomb-45 ${ }^{\circ}$ screen combination and trailing edges of turning vanes on lateral profiles of mean velocity and turbulence intensity in high turbulence flow condition 


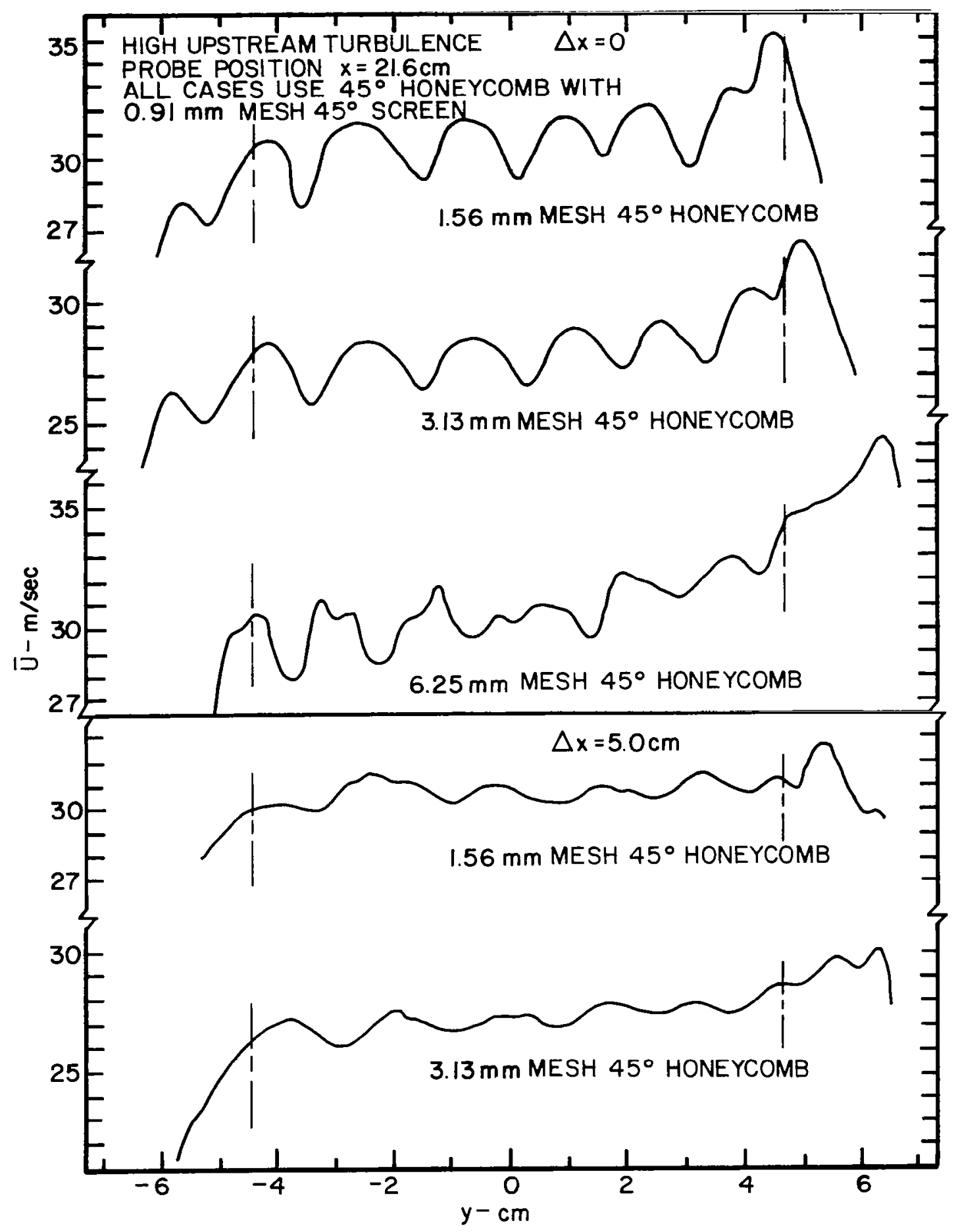

Figure 10. Effect of $45^{\circ}$-honeycomb mesh on lateral profiles of mean velocity for a $45^{\circ}$ honeycomb $45^{\circ}$ screen combination with no separation from turning vanes, $\Delta x=0$, and $\Delta x=5.0 \mathrm{~cm}$ in $\mathrm{high}$ turbulence flow condition 


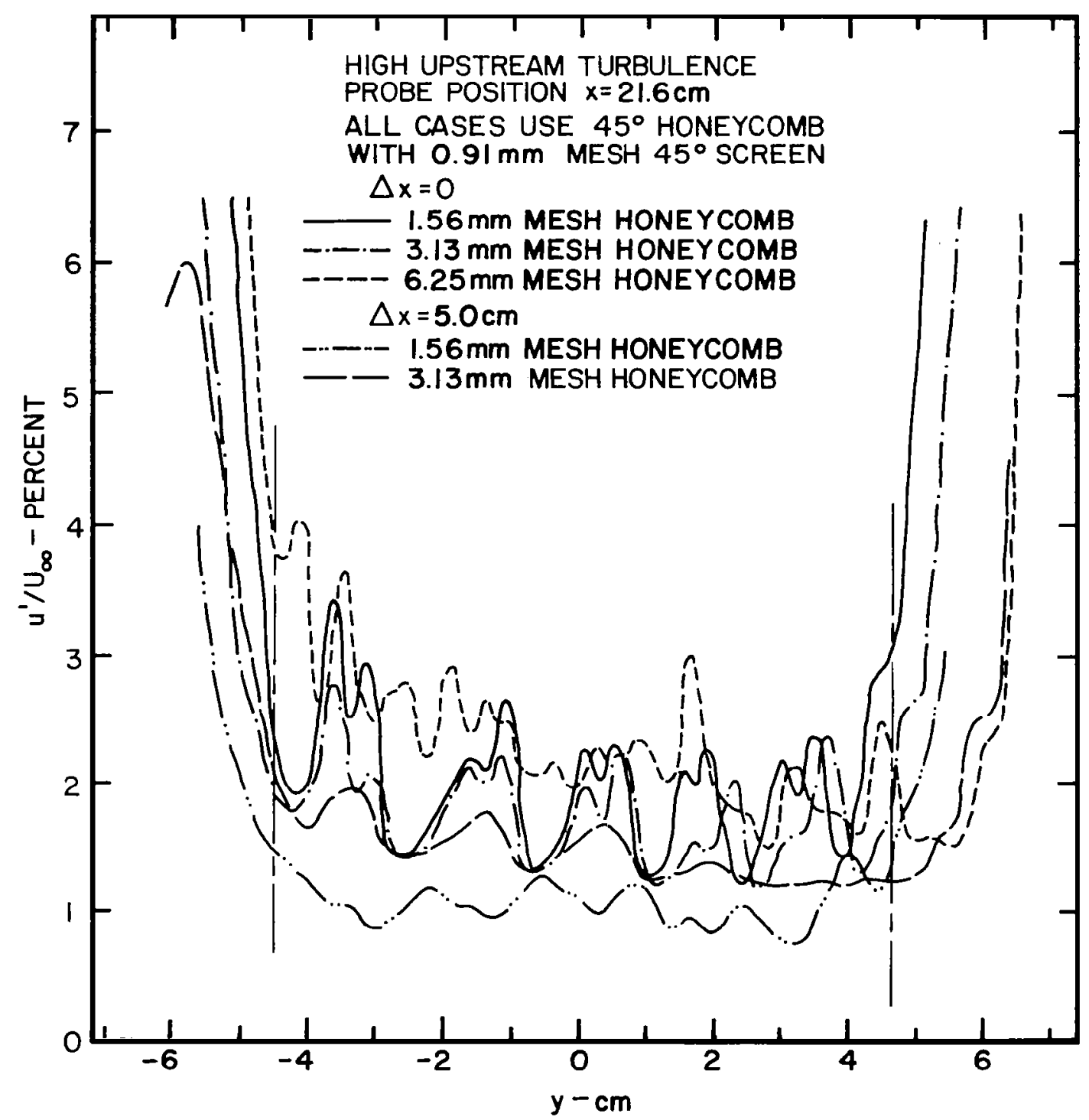

Figure 11. Effect of $45^{\circ}$-honeycomb mesh on latcral profiles of turbulence intensity for $245^{\circ}$ honeycomb-450 screen combination with no separation from turning vanes, $\Delta x=0$, and $\Delta x=5.0 \mathrm{~cm}$ in high turbulence test flow condition 


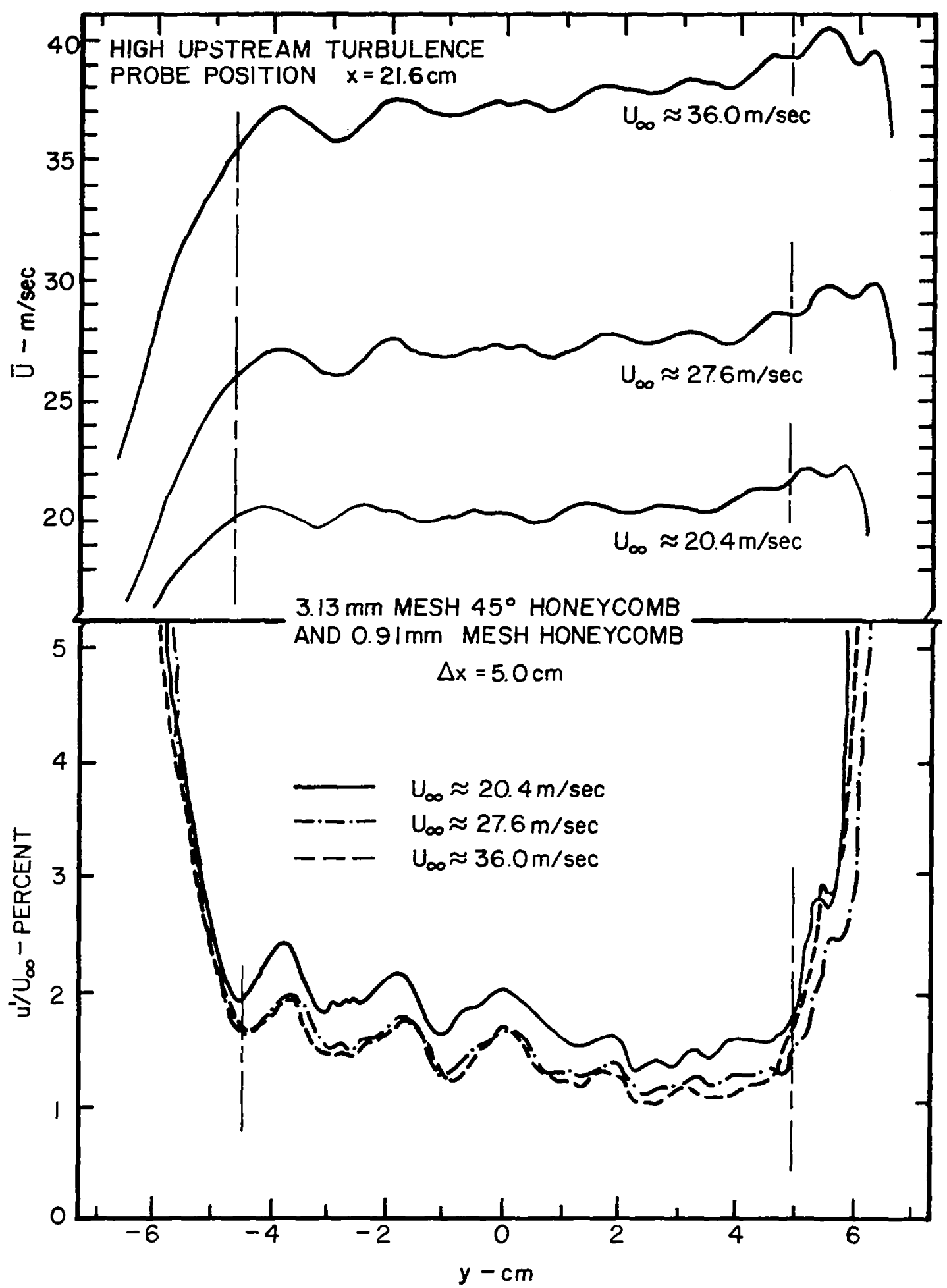

Figure 12. Lateral profiles of mean velocity and turbulence intensity for three free-stream velocities with a $45^{\circ}$ honeycomb$45^{\circ}$ screen combination downstream of turning vanes and separation $\Delta \mathrm{x}=5.0 \mathrm{~cm}$ 


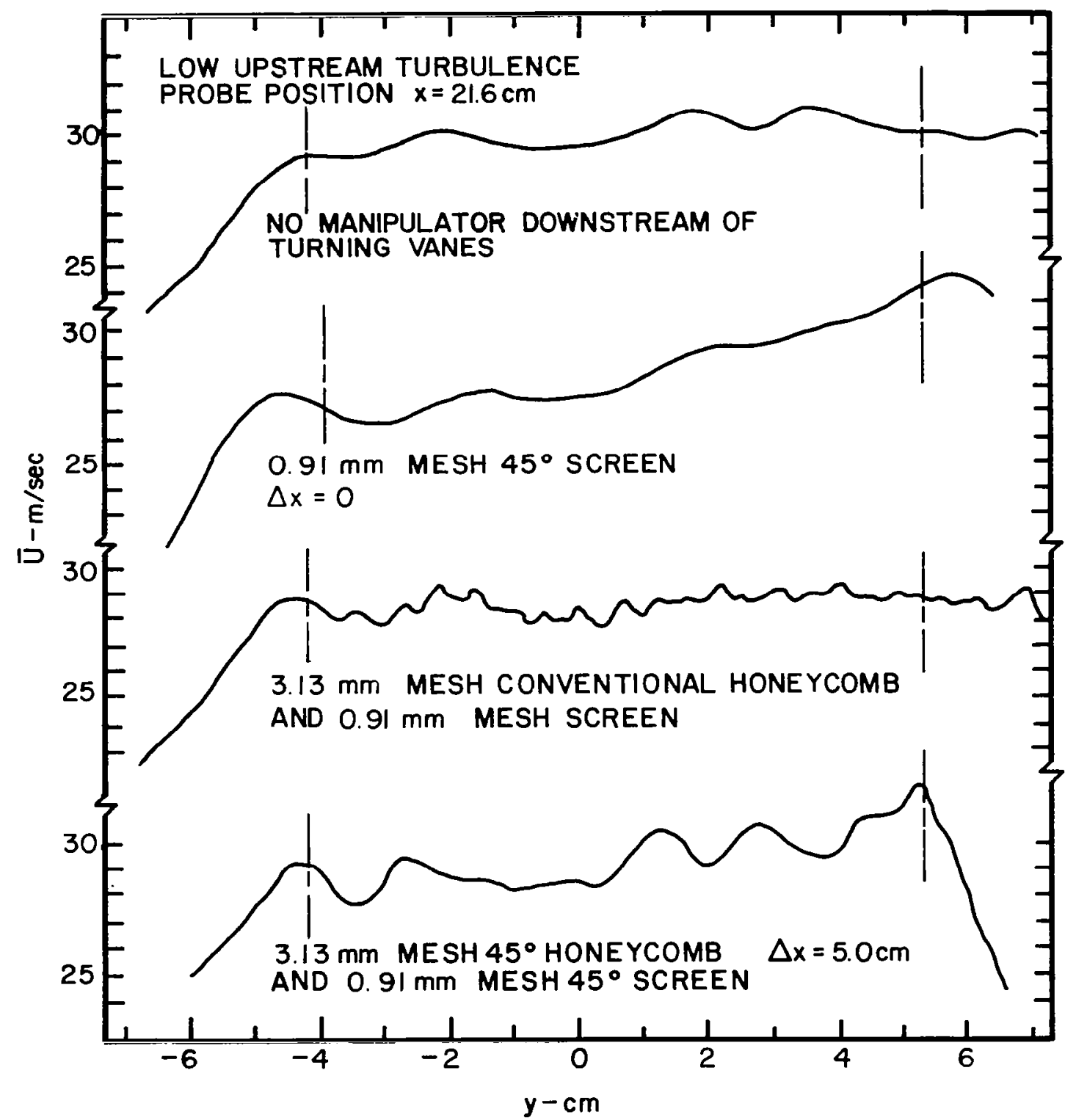

Figure 13. Effect of using no manipulator, a $45^{\circ}$-screen, a conventional honeycomb-screen combination, and a $45^{\circ}$ honeycomb$45^{\circ}$ screen combination downstream of turning vanes on lateral profile of mean velocity in low turbulence flow condition 


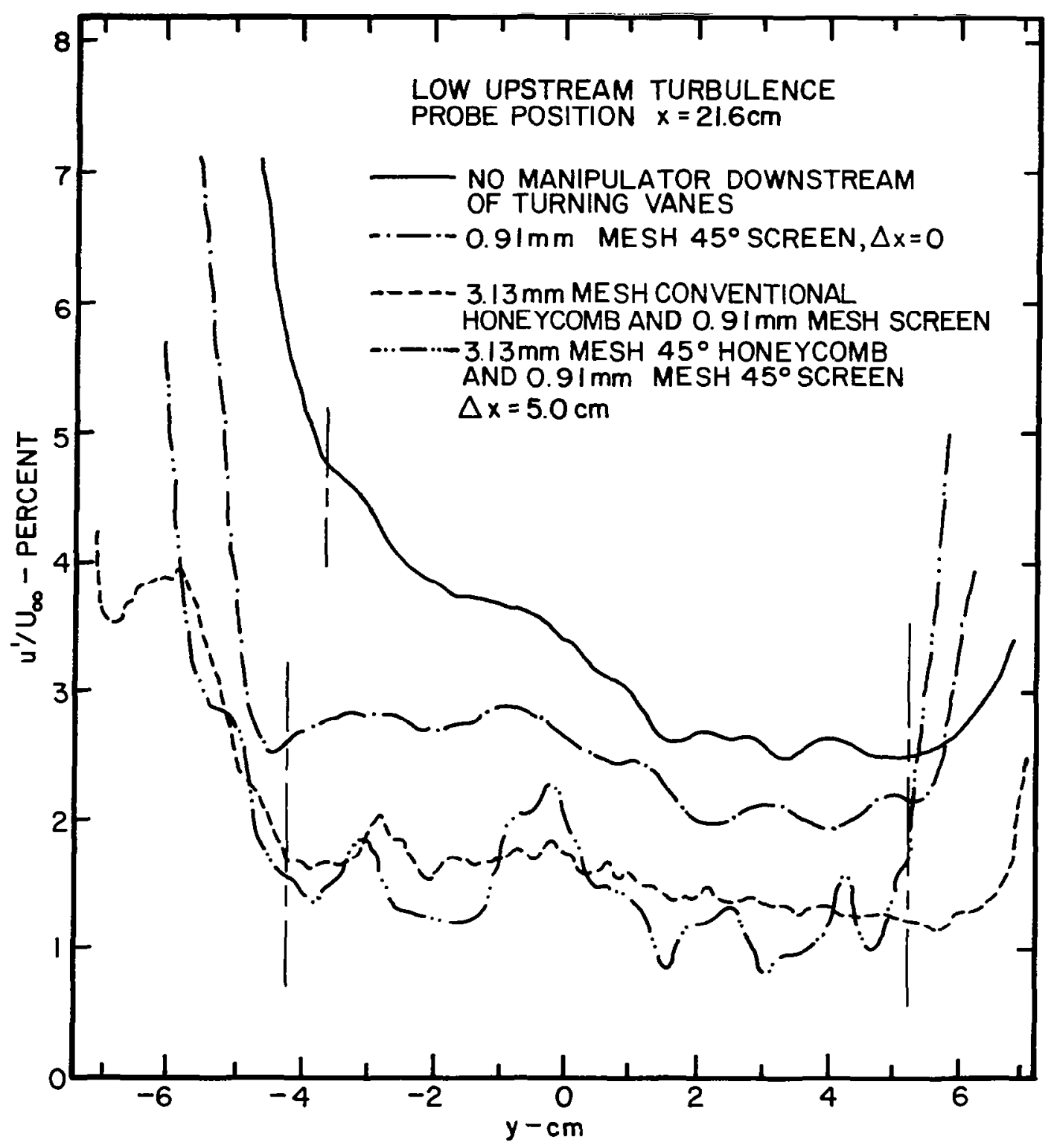

Figure 14. Effect of using no manipulator, a $45^{\circ}$-screen, a conventional honeycomb-screen combination, and a $45^{\circ}$ honeycomb$45^{\circ}$ screen combination downstream of turning vanes on lateral profile of turbulence intensity in low turbulence flow condition 


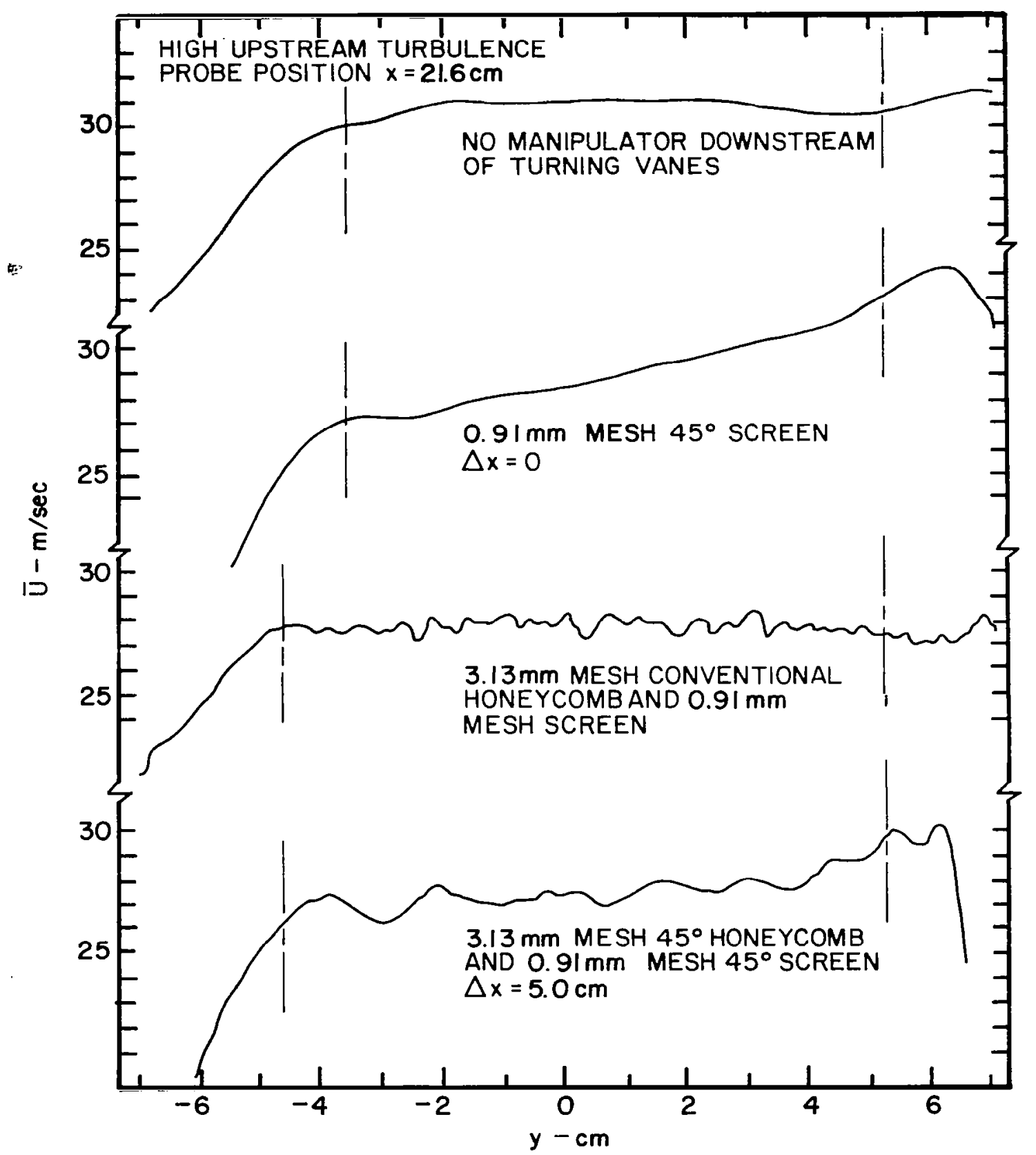

Figure 15. Effect of using no manipulator, a $45^{\circ}$-screen, a conventional honeycomb-screen combination, and a $45^{\circ}$ honeycomb$45^{\circ}$ screen combination downstream of turning vanes on lateral profile of mean velocity in high turbulence flow condition 


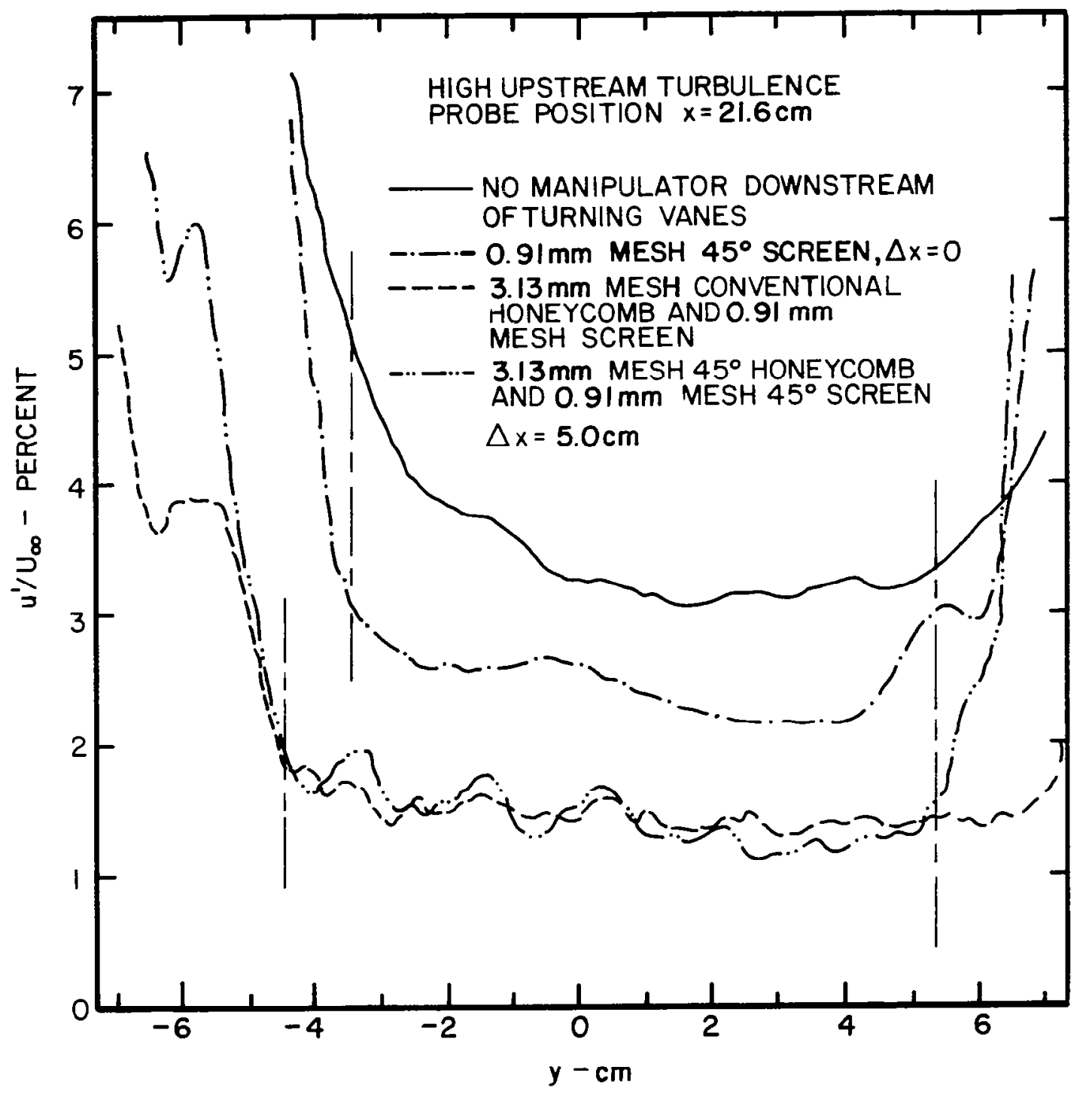

Figure 16. Effect of using no manipulator, a $15^{\circ}$-screen, a conventional honeycomb-screen combination, and a 45 honeycomb$45^{\circ}$ screen combination downstream of turning vanes on lateral profile of turbulence intensity in high turbulence flow condition 


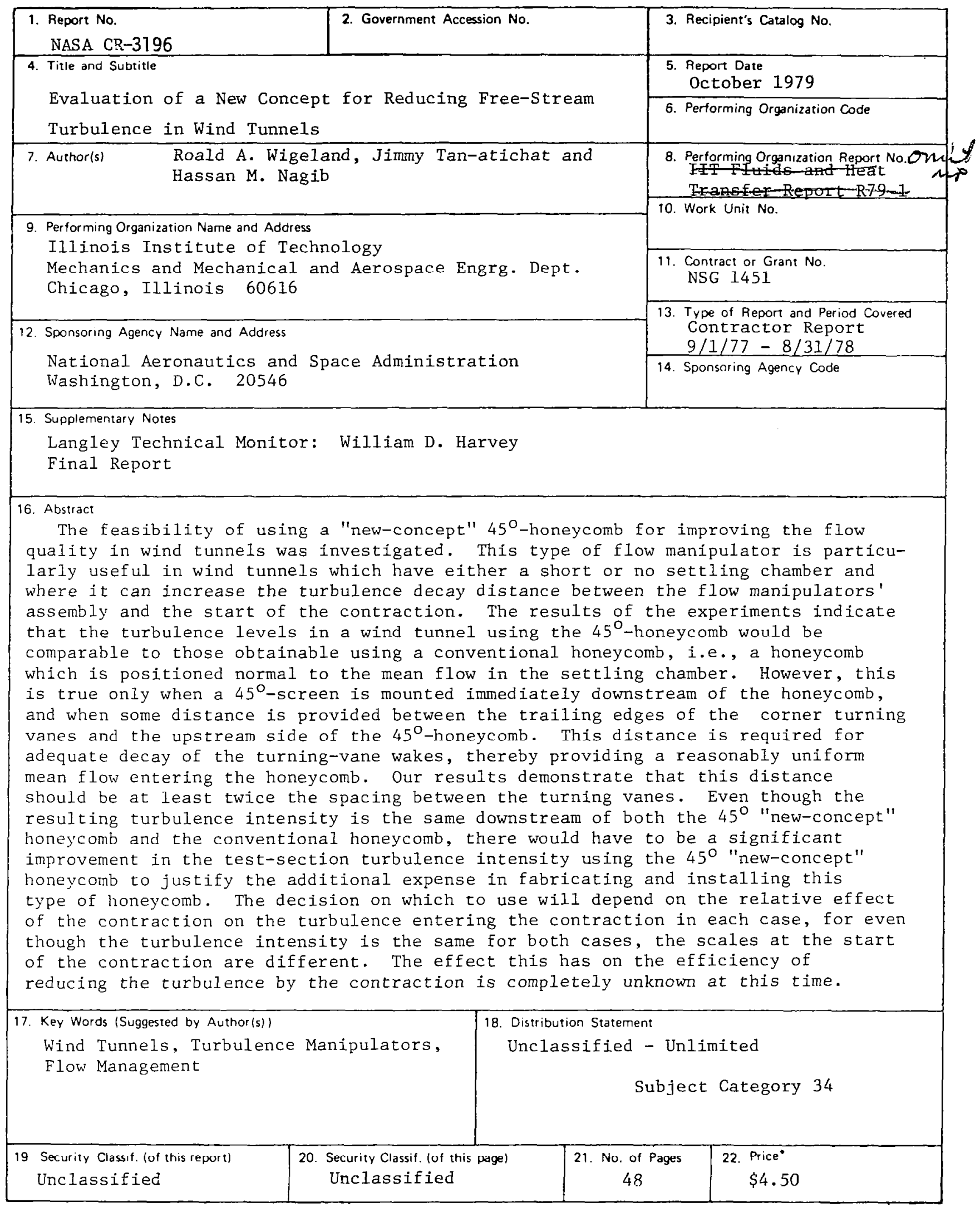

- For sale by the National Technical Information Service. Springfield. Virginia 22161 